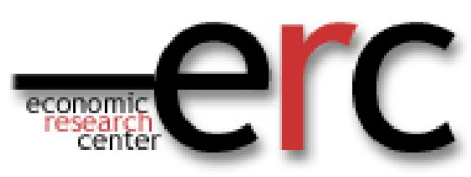

ERC Working Papers in Economics 12/01 Jan 2012

\author{
LABOR MOBILITY ACROSS \\ THE FORMAL/INFORMAL DIVIDE IN TURKEY: \\ EVIDENCE FROM INDIVIDUAL LEVEL DATA
}

\author{
Aysit Tansel \\ Department of Economics \\ Middle East Technical University \\ Ankara 06531 Turkey \\ Email: atansel@metu.edu.tr \\ Tel: 90.312 .2102057 \\ Fax : 90.312.210 7964 \\ Institute for the Study of Labor (IZA) Bonn, Germany \\ and \\ Economic Research Forum (ERF) Cairo, Egypt \\ and \\ Elif Oznur Kan \\ Department of International Trade \\ Cankaya University, Ankara, Turkey \\ E-mail: elifoznurkan@cankaya.edu.tr \\ Telephone: 90.312.233 1208 \\ Fax: 90.312.233 1027
}




\title{
LABOR MOBILITY ACROSS THE FORMAL/INFORMAL DIVIDE IN TURKEY: EVIDENCE FROM INDIVIDUAL LEVEL DATA*
}

\author{
Aysit Tansel \\ Department of Economics \\ Middle East Technical University \\ Ankara 06531 Turkey \\ Email: atansel@metu.edu.tr \\ Tel: 90.312.210 2057 \\ Fax : 90.312.210 7964 \\ Institute for the Study of Labor (IZA) Bonn, Germany \\ and \\ Economic Research Forum (ERF) Cairo, Egypt \\ and

\section{Elif Oznur Kan} \\ Department of International Trade \\ Cankaya University, Ankara, Turkey \\ E-mail: elifoznurkan@cankaya.edu.tr \\ Telephone: 90.312 .2331208 \\ Fax: 90.312.233 1027
}

December, 2011

Keywords: Labor market dynamics, informality, Markov processes, multinomial logit, Turkey

JEL Classification: J21, J24, J40, J63, 017

\footnotetext{
* This paper is based on Elif Oznur Kan's PhD thesis (see Kan, 2011) prepared under the supervision of Aysit Tansel at the Department of Economics, METU. Elif Oznur Kan would like to thank Hakan Ercan, Tolga Omay and Ozan Acar for helpful comments on her PhD thesis. Thanks are also due to Murat Karakas, responsible of Labour Force and Living Conditions Group at the Turkish Statistical Institute for his kind help in implementing this study. Any errors are our own.
} 


\begin{abstract}
Informality has long been a salient phenomenon in developing country labor markets, thus has been addressed in several theoretical and empirical research. Turkey, given its economic and demographic dynamics, provides rich evidence for a growing, heterogeneous and multifaceted informal labor market. However, the existing evidence on labor informality in Turkey is mixed and scant. Along these lines, we aim to extend the existing literature by providing a diagnosis of dynamic worker flows across distinct labor market states and identifying the effects of certain individual and job characteristics on variant mobility patterns. More specifically, we first develop and discuss a set of probability statistics based on annual worker transitions across distinct employment states utilizing Markov transition processes. As Bosch and Maloney (2007:3) argue: "labor status mobility can be assumed as a process in which changes in the states occur randomly through time, and probabilities of moves between particular states are governed by Markov transition matrices". Towards this end, we will use the novel Income and Living Conditions Survey (SILC) panel data set to compute the transition probabilities of individuals moving across the labor market states of formal-salaried, informal-salaried, formal self-employed, informal self-employed, unemployed and inactive. The transitions analysis is conducted separately for two, three and four year panels pertaining to 2006 to 2007, 2006 to 2008 and 2006 to 2009 transitions; for total, male and female samples; and lastly for total and non-agricultural samples. In this way, we aim to contribute to the limited body of stylized facts available on mobility and informality in the Turkish labor market. Next, we conduct multinomial logit regressions individually for each set of panel to identify the impact of individual characteristics (i.e. gender, age, education level, work experience, sector of economic activity, firm size, number of other household members, having/not having children, rural/urban) underlying worker transitions. The results reveal several relationships between the covariates and likelihood of variant transitions, and are of remarkable importance for designing policy to address labor informality and reduce its negative externalities.
\end{abstract}




\section{INTRODUCTION}

Informality has long been a salient phenomenon in developing country labor markets, thus has been addressed in several theoretical and empirical research since the 1950s. In the early literature, most analyses hinged on static and aggregate approaches. With the introduction of advanced panel data sets and techniques, more profound and thorough dynamic research was empowered. Mobility analysis, in particular, now became readily available and led to a paradigm shift in the labor markets literature. In particular, it provided the means for investigating the implications of and motivations for workers transitions into and out of informal employment, examining the determinants of duration and turnover rates in the informal sector and the extent to which and how specific individual and job characteristics influence worker flows. Along these lines, mobility analysis illuminated the abstract informality phenomenon to a remarkable extent.

In this study, we implement the mobility analysis to the Turkish labor market with a specific emphasis on informality. Turkey, given its economic and demographic dynamics, provides rich evidence for a growing, heterogeneous and multifaceted informal labor market (Tansel, 1998; Tansel, 2000; Bulutay and Tasti, 2004; Ozdemir et al., 2004; DPT, 2009; Kenar, 2009; Aydin et al., 2010; World Bank, 2010). However, the existing evidence on labor informality in Turkey is mixed and scant. Data limitations and conceptual obscurity have hindered detailed analyses. Along these lines, we aim to contribute to the existing literature by providing a diagnosis of dynamic worker flows across distinct labor market states and identifying the effects of certain characteristics (i.e. age, gender, education, work experience, household demographics, economic activity sector, etc.) on variant mobility patterns. To the best of our knowledge, this study is the first such to undertake a labor mobility analysis in the context of formal/informal division in Turkey.

More specifically, we first develop and discuss a set of probability statistics based on annual worker transitions across distinct employment states utilizing Markov transition processes. As Bosch and Maloney (2007: 3) argue: "labor status mobility can be assumed as a process in which changes in the states occur randomly through time, and probabilities of moves between particular states are governed by Markov transition matrices". Towards this end, we will use the novel Income and Living Conditions Survey (SILC) data of 2006, 2007, 2008 and 2009 to compute the transition probabilities of individuals moving across six different labor market states. Indeed, the panel feature of SILC allows us to trace same individuals in the working age population over two, three and four years between 2006 and 2009. In this framework, we first compute the transition probabilities separately for two, three and four year transitions pertaining to 2006 to 2007, 2006 to 2008 and 2006 to 2009 transitions; for total, male and female samples; and lastly for total and non-agricultural samples. We define six labor market states as formal-salaried, informal-salaried, formal self-employed, informal 
self-employed, unemployed and inactive. In this way, we aim to contribute to the limited body of empirical stylized facts available on mobility and informality in the Turkish labor market. Indeed, we find evidence that mobility patterns are fairly similar across different time spans. Also, the probability of remaining in initial state is higher than probability of transition into another state for all the labor market states, except for unemployment. Together, these findings depict that Turkish labor market has a relatively static nature. Regarding the direction and degree of outflows, we note that there is very limited mobility into the formal-salaried state. This evidence is suggestive of entry barriers to and/or preference for formal-salaried employment, thereby confirming the traditional dualistic theory of formal and informal labor markets in the Turkish context. Another noteworthy pattern pertains to informal self-employed who display only minimal mobility into salaried employment. This finding is of great importance since it reveals the nature of informal self-employment in Turkey. Concurrent with transition statistics for the non-agricultural sample, we may conclude that informal self-employment is mostly agricultural and female. Therefore, informal self-employment in Turkey differs from that in Brazil, Mexico and Argentina where it is mostly voluntary (Bosch and Maloney, 2010)

The transition analysis, however, is mostly descriptive in nature and falls short of explaining the underlying dynamics. In order to examine the nature of labor mobility patterns in more detail, we estimate six multinomial logit models individually for each labor market state adopting several individual, household and job characteristics as explanatory variables. The results reveal several relationships between the covariates and likelihood of variant transitions. Particularly, gender, education and sector of economic activity are observed to display significant effects on mobility patterns. These findings are of great importance for designing policies to effectively address labor informality in Turkey.

In line with the recent literature, we define six labor market states to be formal salaried (FS), informal salaried (IS), informal self-employed (ISE), formal self-employed (FSE), unemployed (U), and inactive $(\mathrm{N})$. This categorization facilitates investigating various possible transitions into and out of informal employment. Particularly, disentangling the formal/informal divide further into salaried/selfemployed subgroups provides the means for assessing the extent to which and how informality prevails in different forms. Moreover, the inclusion of unemployed and inactive categories enables a more comprehensive labor market analysis, as informal employment displays substantial transitivity into/out of these non-employment states. To the best of our knowledge, this study offers the first such exclusive analysis in the context of the Turkish labor market.

The remainder of the paper is organized as follows: Section 2 provides a brief survey of literature on mobility in the formal/informal labor markets. Section 3 describes the data and definition of main variables used in the study. The methodology and results of transition analysis are presented in 
Sections 4.1 and 4.2 respectively. The methodology of multinomial logit models is explained in Section 5.1 and estimation results are discussed in Section 5.2. Finally, Section 6 provides a summary of the main findings and implications for policy.

\section{SURVEY OF LITERATURE}

As Perry et al. (2007:57) have pointed out: "static summary statistics of the allocation of workers obscure important aspects of the dynamism of worker flows among sectors". The introduction of reliable panel data sets gave rise to a new set of techniques in the informality literature. Starting with the pioneering work of Maloney (1999), several attempts have been made to model labor mobility using transition matrices constructed from probabilities of actual movements of the same individuals across distinct labor market states. In this way, more profound analyses on labor market dynamics were made possible.

Maloney (1999), in his seminal work, examines mobility patterns between different sectors using Mexican panel data. He aims to test the traditional dualistic theory of formal and informal labor markets. He analyzes the worker transition patterns across six sectors of work including the formal salaried, informal salaried, self-employed, contract workers, out of labor force and unemployed. $\mathrm{He}$ first calculates the raw probability of moving from an initial sector to a terminal sector, and then standardizes it by the terminal sector size, separation rates from the initial sector and job openings in the terminal sector. He finds that the standardized mobility indices $\left(\mathrm{V}_{\mathrm{ij}}\right.$, as he names) depict symmetrical flows across all sectors of work and that labor mobility and turnover rates are high. To this extent, he argues that urban labor markets exhibit an integrated structure, as opposed to a dualistic one. This implies low formal sector turnover rates, largely unidirectional flows from informal to formal sectors. Moreover, Maloney investigates the dynamics underlying worker transitions with a multinomial logit model. He uses experience, schooling and the initial real wage as covariates to influence the probabilities of moving from one sector to another. The results, as Maloney reports, also support an integrated labor market structure.

In a recent comprehensive study, Bosch and Maloney (2010) use panel data from Argentina, Brazil and Mexico in order to analyze and compare labor market dynamics. Using continuous time Markov transition processes derived from an underlying discrete time counterpart, they compute transition statistics across five labor market states which comprise out of labor force, unemployed, informalsalaried, formal-salaried and self-employment. These statistics include the raw intensities (Q-statistic) of transition, the propensities (R-statistic) of transitions conditional on turnover rate, the adjusted propensities (C-statistics) controlling for turnover and job vacancies, a general mobility index and the average duration in each sector (Bosch and Maloney, 2010: 624). The intensities point out three main 
patterns. First, duration is highest in formal-salaried and lowest in informal-salaried, informal-salaried to formal flows far higher than the reverse flows. Second, mobility between informal-salaried and selfemployed are significantly higher than that of formal-salaried and self-employed. As for the propensities, the authors argue that transition patterns are reversed in some cases, indicating a closer resemblance of an integrated market view. Considering the adjusted propensities, the patterns are further smoothened and appear to be fairly symmetrical between formal-salaried and selfemployment, and also between formal-informal salaried flows. When flows are disaggregated across age and business cycle, Bosch and Maloney (2010:631) conclude that "a substantial part of the informal sector, particularly the self-employed, corresponds to voluntary entry, although informalsalaried work appears to correspond more closely to the standard queuing view, especially for young workers".

Gong et al. (2004) explore the mobility patterns in five urban cities of Mexico using two separate fivewave panels over the period 1992-1995. The purpose is to determine the mobility patterns and their underlying dynamics associated with individual characteristics and business cycles. Also, they question whether the transitional evidence support a traditional view of informal work as the disadvantaged sector. Gong et al. (2004:10) first present quarterly transition matrices for flows between non-employment, informal-sector employment and formal-sector employment for both panels. They find the probability of transitions between not working and informal sector to be higher than that of not working and formal sector. Also, they note that probability of remaining in the formal sector is significantly higher than that of informal sector. Then, a reduced form dynamic multinomial panel logit model with random effects is run to examine the influence of one's age, education, gender, ethnicity, region and previous labor market state. The results display a positive relationship between level of education and formal sector employment, a negative (positive) relationship between the income of other family members and informal sector employment (non-employment). A novel approach is used to calculate the simulated transition probabilities for different individual characteristics and market conditions. Overall, Gong et al. (2004) find evidence in favor of the traditional labor market view where informal sector is inferior, a temporary queuing device before transition into formal work, and entry and exit rates of formal employment are relatively low.

With the same purpose of assessing whether labor mobility patterns are in line with a traditional labor market view and how they are affected by individual characteristics, Bernabè and Stampini (2009) analyze quarterly 1998-1999 panel data for Georgia. They consider six labor market states comprising inactivity, unemployment, formal wage employment, informal wage employment, self-employment and farming. All individual transitions even if observed at least once are pooled regardless of the period in order to build the transitions matrix. In addition to calculating the standard transition probability indices, a new statistic for testing labor market segmentation is introduced. The share of 
temporary mobility, defined as those workers who move to another state at any time but found in the original state at the final interview relative to workers who made at least one transition, is deemed to measure the desirability of each status (Bernabè and Stampini, 2009:385). Six multinomial regressions are run for each state of departure to scrutinize the effects of several individual characteristics on the likelihood of each transition. The evidence overall suggests that informal employment is involuntary and more volatile than formal employment. On the other hand, the self-employed are found to involve both voluntary and subsistence activities. Age, gender, education and urban/rural variables are confirmed to be statistically significant in mobility patterns. Bernabè and Stampini (2009) also contribute to the existing labor mobility literature by accounting for different macroeconomic conditions and farming activities.

Pagés and Stampini (2009) contribute to the existing literature on labor market segmentation and mobility in several ways. They provide a comparative analysis of labor mobility patterns for six countries. The sample includes Argentina, Mexico and Venezuela, which have been addressed by several previous researches; and extends to Albania, Georgia and Ukraine which have been understudied. Instead of running a dynamic multinomial logit regression, the authors estimate transition matrices separately for skilled and unskilled labor as measured by education level. The main contribution of the paper, however, is a new benchmark mobility index that complements the standard transition probabilities. The measure accounts for the size and job openings in initial and terminal states, thereby eliminates all mobility barriers, and renders all states to be equally preferred and equally likely to become the destination sector. Pagés and Stampini (2009:386) compare the standard transition matrix to a steady state matrix and a benchmark transition matrix. The evidence displays a high level of mobility between formal-salaried and informal-salaried, but a low level of mobility between self-employed and formal-salaried. The skill levels are found to be statistically insignificant in affecting mobility patterns.

Duryea et al. (2006) provides an empirical mobility analysis of nine countries of Albania, Georgia, Hungary, Poland, Russia, Ukraine, Argentina, Mexico, and Venezuela. Informality is mainly defined based on the social security definition and contract status in countries where data is lacking. Conditional annual probabilities of moving from an initial sector $i$ to another sector $j$ are calculated to form transitional matrices for each of the six labor market states. The evidence indicates that unemployment is more persistent in transition countries, formal sector jobs have a higher duration than informal sector jobs, transitions into unemployment is higher from informal sector as compared to the formal sector. Furthermore, mobility within salaried employment states (i.e. formal-salaried and informal-salaried) exceeds that of between salaried employment and self-employment.

Woltermann (2002) studies the search methods in Brazilian labor market using the Monthly 
Employment Survey of 1999. The study, however, deviates from the literature by considering a segmented labor market (formal employment, informal employment, self-employed, inactive and searching) rather than a standard dualistic "working" or "searching" approach. He examines the impact of different job search methods, education, gender and household head position on labor market transitions through a multinomial logit model. By definition, searching (unemployment) is taken to be the reference category, and only transitions out of the searching status are considered. In this way, Woltermann (2002) tests whether the likelihood of moving to a new state versus remaining in searching status is affected by any of the explanatory variables.

Calderon-Madrid (2000) analyzes transitions from the second to the third quarter of 1993, 1995 and 1997 in Mexico. He identifies six sectors or job statuses to be formal and informal sectors, unemployment, out of the labor force, self-employment, paid by commission or percentage, and unpaid jobs. He finds a) that the time spent in a job and the so-called four and six-year retention rates are short relative to OECD countries; b) that between $15 \%$ and $20 \%$ of wage earners in the formal sector move out to another job status in only one quarter, and that the figures for other job statuses (informal workers, self-employment, unpaid jobs, etc.) are much higher; and c) that the share of each job status within the total population did not significantly change, albeit a high level of individual movements among job statuses. This last feature implies that the spaces left by the flow of persons out of one job status and into another one are to a great extent filled by a flow of persons moving in the opposite direction. In order to explain further the dynamics behind the transitions, he estimates hazard functions. The analyses show that in informal employment and self-employment job statuses, persons with formal education spend less time compared to those without formal education. Through estimation of hazard functions, Calderon-Madrid finds that the median time spent by workers in the formal sector relative to the median time spent by those in the informal sector is approximately 3.5 times higher.

Maloney (1998), sketching patterns of mobility among sectors for 1987-1991 panel data, posits that a high degree of mobility of workers characterized the Mexican labor market. His analysis is based on a transition matrix that enables him to compare a person's job status at a certain point of time with the status that he or she had twelve months earlier. Women and persons with a level of education above high school are exluded.

Krstić and Sanfey (2007) examine the labor mobility in Bosnia and Herzegovina (BH), employing two waves of panel data from 2001 and 2004 Living Standard Measurement Study (LSMS). They consider a wider range of labor statuses; namely informal employees, informal self-employed, farmers on own farm and unpaid family workers make up the informal employment; formal wage employees and formal self-employed make up the formal employment; unemployed and inactive make up the 
remaining labor force. First by grouping informal and formal employment into one category, and using the "Shorrocks index", Krstić and Sanfey (2007) compare the overall mobility level relative to other transition countries and find mobility to be high in Bosnia-Herzegovina. Next, they further decompose labor flows into formal-informal employment sectors and wage- and self-employment categories. The main findings are that a) informal workers who moved into formal employment remained in the same sector, b) almost all informal employees who became formal workers remained in the same employment type, c) agriculture though being the least mobile sector exhibited significant flows between farmers and unpaid family workers (Krstić and Sanfey, 2007:320). In order to scrutinize the dynamics of employment transitions, a probit regression is run. The explanatory variables (i.e. gender, age and age squared, marital status, completed level of education, resident status and health status, size of the household, other household members employment status, consumption quintiles and location, sector of economic activity and whether the worker remained in the same job) are used to explain the probability of moving from informal to formal employment. Education level, service sector, remaining in the same job and residential status variables are found to have significant explanatory power.

Lehmann and Pignatti (2007) investigate employment flows in Ukraine using a rich data set from 2003-2004 Ukrainian Longitudinal Monitoring Survey (ULMS). They estimate multinomial logit transitions both within and between formal and informal employment statuses. There are several explanatory variables such as gender, age, schooling, tenure, part-time, voluntary-involuntary, marital status, number of children and region. The results vary according to the type of transition. Next, they derive transition matrices separately for 4 and 6 labor market states following Maloney (1999). That is, they estimate the "P" -matrices of raw transition probabilities, "Q" -matrices of destination sector size standardized probabilities and "V" -matrices of state occupancy duration adjusted "Q"-matrices. The main findings are that formal employment is the most desirable state, informal employment and unemployment are queuing stages for formal employment and labor market is segmented.

The methodology of Maloney (1999) is applied to Argentinian case by Canavire-Bacarreza and Soria (2007) for the period 1998 to 2005. Multinomial logit regression models and conditional probability matrices for labor market transitions are estimated. The purpose is to test the effects of economic crises on the evolution of labor mobility. The evidence indicates that more educated people enter easier to formal labor markets. Moreover, they tend to adjust their wages and push out of the market less educated people during the crises when their probability of entering to formal labor market reduces.

\footnotetext{
2 "The Shorrocks index is proportional to the fraction of individuals who changed their labour market status within a given period. It is calculated as $\mathrm{S}=(\mathrm{n}-\operatorname{tr}(\mathrm{P})) /(\mathrm{n}-1)$, where $\mathrm{n}$ is the number of states and $\operatorname{tr}(\mathrm{P})$ is the trace of transition matrix $\mathrm{P}$. $\mathrm{S}$ takes the values in the interval $[0, \mathrm{n} / \mathrm{n}-1] ; \mathrm{S}=0$ when nobody changed their status and $\mathrm{S}=\mathrm{n} / \mathrm{n}-1$ when everybody changed their status". (Krstić and Sanfey, 2007:318)
} 
Bigsten et al. (2007) study the degree of segmentation and structural dynamics of the Ethiopian labor markets between 1994 and 2004. In this regard, they examine the evolution of earning gaps, worker transitions and state dependence in sector choice over time. The main labor market statuses are unemployment, public/private sector employment, formal/informal sector employment and wage/self employment. In addition to computing the raw sample transition matrices, Bigsten et al. (2007) estimate dynamic binary sector choice models for four labor market states. However, the analysis is limited to binary techniques and dichotomies. That is, they track the degree of segmentation across different time pairings and estimate probit models for binary sector choices. The main findings are that workers' mobility has increased over time, state persistence has decreased and sensitivity to earning gaps in sector choice has augmented.

\section{DATA}

The data set used in this analysis is drawn from the "Income and Living Conditions Survey (SILC)", which has been conducted by the Turkish Statistical Institute (TurkStat) since 2006. The novel, nationally representative, rich, panel nature of the survey makes it unique and invaluable for the aim and methodology of the study. It provides detailed information on the employment status, social security coverage, working hours, labor and other income, demographic characteristics, living conditions, job characteristics, and socioeconomic conditions of the subjects. The survey results have only recently been released in micro data sets, thus to our knowledge have not yet been used in any other studies.

SILC is designed as a rotating panel in which the sample of households and corresponding individuals are traced annually for four consecutive years. Each year the survey is conducted for four subsamples. One subsample is removed and replaced by a new subsample in each year. The samples are selected and assigned survey weights so as to be representative of non-institutionalized Turkish resident population. A two-stage stratified sampling procedure is used in sample selection. The interviews are administered once every year. The sample size is designed considering possible non-response, thereby no replacement is undertaken.

The survey results are published annually in both cross-section and panel data set formats. The analysis below focuses mainly on the years 2006, 2007, 2008 and 2009, since the micro data set for the following years are not yet released. The original cross-sectional samples consist of 30,186 individuals for 2006; 30,263 individuals for 2007; 31,121 individuals for 2008 and 32,539 individuals for 2009. For the specific aim and methodology of our study, the panel samples are modifed in a way to comprise only the labor force between 15-64 years of age who are present in at least two 
consecutive years of the survey. That corresponds to 18,343 individuals for $2006-2007 ; 11,462$ individuals for 2006-2008; 5,422 individuals for 2006-2009.

Subsuming a rich set of information on household expenditure, income and assets, employment and living conditions, SILC is invaluable for implementing a detailed labor mobility analysis for Turkey. First and foremost, the questionnaire allows us to distinguish between employed/non-employed, salaried/self-employed, formal/informal. Along these lines, we identify six different labor market states: formal salaried, informal salaried, formal self-employed, informal self-employed, unemployed and inactive. As regards to defining informality, the first internationally agreed operational definition was adopted in the $15^{\text {th }}$ International Conference of Labor Statisticians (ICLS) in 1993. According to this definition, informal employment was defined as comprising "all jobs in informal sector enterprises, or all persons who, during a given reference period, were employed in at least one informal sector enterprise", with informal sector enterprises meaning private unincorporated enterprises, i.e., enterprises that are "not constituted as separate legal entities independently of their owners, and for which no complete accounts are available that would permit a financial separation of the production activities of the enterprise from the other activities of its owner(s)" (Hussmanns, 2005:3). Put differently, informality was ascribed to small-scale enterprises; enterprises operating without a legal status and/or employing unregistered workers; and family enterprises with unpaid family workers and the self-employed (Aydin et al., 2010:3). The ILO definition was later extended to comprise self-employed in informal enterprises (i.e. workers, employer/owner of small firms, ownaccount workers, unpaid contributing family members); and wage employment in informal jobs (i.e. employees in informal enterprises, casual and domestics workers, industrial outworkers) (Chen, 2007). A third definition, in official ILO terms, considers an employment relationship as informal if it is not subject to labor legislation, social protection, taxes or employment benefits (Hussmanns, 2005:7). The social security and contract status are by and large the two most common measurement criteria in applied research.

The definitions are adopted to be as consistent as possible to the existing theoretical and empirical literature. Employees working for a wage/salary are defined as formal-salaried if they are registered at the social security institution for their current job, and informal-salaried when they are not. Ownaccount workers and unpaid family workers form the self-employed category, which is further divided into formal self-employed if registered at the Social Security Institution and informal self-employed if not. We identify unpaid family workers to be informal self-employed as in Pages and Stampini (2009:389). Employers are excluded from the sample, as the number of observations is insufficient to perform any reasonable analysis. Unemployed category comprises individuals who are not working, but actively searching for a job. Individuals are inactive if they are neither working nor searching for a job. In particular, students, retirees, seasonal workers, old or those unable to work, domestic workers 
are classified as inactive. By disaggregating the labor force into multiple subcategories, we are able to scrutinize the different patterns of labor mobility defined as worker transitions between distinct labor market states.

The frequencies and shares of each labor market category for 2006, 2007, 2008 and 2009 are given in Table 1a. The numbers are quite similar across four years, except for the notable rise in the share of formal-salaried category. As Table 1a illustrates, inactives make up the largest share of total sample, reaching almost 50 percent. Informal self-employed and formal-salaried stand at similar shares of approximately 18 and 16 percents of the total sample, respectively. The remaining sample is comprised of informal salaried at around 10 percent, unemployed at 5 percent and formal selfemployed at only 3 percent.

A gender breakdown of distribution analysis is of significant importance in the Turkish labor market. Indeed, the incidence of inactive women still stands as a major virtue of the Turkish labor market, thence distorts most aggregate labor market figures. Along these lines, Table $1 \mathrm{~b}$ and $1 \mathrm{c}$ break down the labor force into men and women, and recalculates the labor market distribution accordingly. As expected the inactivity rate increases to $70 \%$ for women, and falls to $22 \%$ for men. That proves the magnitude of inactive women to be a fundamental driving force behind the labor market dynamics. Indeed, the sample proportions of all other labor market states are considerably lower for women compared to that of men. As regards to informality, the figures also reveal an evident fact that almost two thirds of those women who are employed are informal, while men exhibit a more or less equal distribution across informal and formal employment. Further decomposition displays the fact that men are mostly employed in salaried positions, and women in self-employment positions. It is also noteworthy to mention that women show almost no existence in formal self-employment whereas majority of women work as informal self-employed. This fact is a mere reflection of unpaid women family workers in agriculture.

In addition to employment, SILC contains information on the demographics of the individuals such as age, gender, education, marital status, occupation, family composition, work experience, health status, economic sector, and detailed information on living conditions. A number of these variables will be used as covariates in the multinomial logit analysis in the further parts of the study.

In order to provide a general picture, labor informality in Turkey is decomposed across time and by a number of key factors ${ }^{3}$. Table 2 details the sample distribution of informality by gender, age, education, marital status, occupation, sector, employment status, firm size, household type and

\footnotetext{
${ }^{3}$ For a more comprehensive decomposition, see Table 3 which details the composition of each of the six labor market states according to multiple variables.
} 
location for 2006 and $2009^{4}$. The decomposition analysis is conducted separately for total employment and non-agricultural employment. The aim is to detach the effects of agricultural sector being 90 percent informal on the dynamics of labor informality. In the descriptive analysis, we follow TurkStat and define the informal employment as those who are employed but not registered to the compulsory Social Security Institution of Turkey (SSI). Accordingly, formal employment refers to those employed who are registered to SSI. Informal employment constitutes approximately over half of the total employment, displaying a decreasing trend through 2006 to 2008 and a slight increase for 2009 which is the year of global economic crisis. Whereas, the picture changes significantly if agricultural workers are excluded from the sample. Non-agricultural informality rates range around 35 percent, reaching its lowest level in 2008. Clearly, informal employment though displaying a decreasing trend, still assumes a sizable weight in the dynamics of the Turkish labor market.

A further breakdown of informality by demographic and socioeconomic factors reveals notable informality patterns. As Table 2 depicts, women are approximately 70 percent informal, where informality among male labor stands at around 45 percent. The shares of informality for men and women exhibit a converging trend towards approximately 40 percent if agriculture is excluded. In terms of age, we see young and elder to be more informal; in both total and non-agricultural employment. Informality appears to be perfectly negatively related to education level, descending from 90 percent for none education to 10 percent for university graduates. Single workers, as opposed to married, tend to be slightly more informal.

The occupational distribution of informality elucidates two notable patterns. It follows that professionals, technicians and clerks are to a large extent formal at around 80-90 percent, whereas skilled agricultural, elementary operations and service workers are mostly employed without being registered to the Social Security Institution (SSI). Needless to say, the figures of informality by occupation are more or less similar for both total and non-agricultural employment. Another central factor underlying the informality dynamics in the Turkish labor market is certainly the sector of economic activity. With regards to sectoral informality, agriculture assumes the lead in terms of informal employment, reaching a level of almost 90 percent throughout the four year period. Construction sector also exhibits a considerable rate of informality. On the other hand, the sectors of mining, utilities, finance, public administration, education, and health remain mostly formal at around 80 to 90 percent. The informality rates by sector remain to be more or less similar across the four years, except for the construction sector exhibiting a which indicates a 10 percent decline in informality from 2006 to 2009.

\footnotetext{
${ }^{4}$ For presentational brevity, Table 2 only reports numbers for 2006 and 2009 which correspond to the initial and final years of our data. The numbers for 2007 and 2008 are available upon request.
} 
The employment status portrays an even more detectable informality pattern. Regular employees are the least informal at around 20 percent, whereas casual employees, own-account workers and unpaid family workers are typically informal. Employers do not exhibit a remarkable distribution in terms of informality, being only slightly more formal. Exclusion of agriculture from the sample does not alter the informality composition significantly, as opposed to what is expected. Casual employees and unpaid family workers, being employed mostly in agriculture, still remain to be highly informal. The decline in informality rates is confined to about 10 percent for the own-account and unpaid family workers when the analysis is restricted to non-agricultural employment.

Firm size displays a perfectly negative relationship with informality, affirming the theory. Accordingly, employment in small firms is typically informal as opposed to that in larger firms being predominantly formal. Excluding agricultural employment, which prevails in smaller firms with ten or less workers, firm size criterion still persists to be negatively associated with informality. Informal employment appears to be more common among non-single households both with/without children. However, the figures somewhat reverses when agriculture is excluded from the sample, concealing a lucid pattern.

To sum up, informality appears to be mostly associated with individuals who are female, young and/or elderly, illiterates and none educated, single, agricultural and/or construction worker, casual employees and/or unpaid family workers, work in small-size firms and live in rural areas. If agriculture is excluded, the formal/informal divide in employment somewhat softens, as most of the above presented informality patterns seems to disappear. These summary statistics set out the preliminary framework of the informality analysis in the Turkish labor market. The sample, as weighted by nationally representative survey weights, characterizes roughly the current aggregate labor market along all dimensions being considered. Furthermore, comparing 2006 and 2009 labor market outlook, we observe that the Turkish labor market displays a somewhat increasing formalization across all dimensions being considered. In order to further delve into its dynamics, the following sections provide transition analysis and multinomial logit estimation.

\section{TRANSITION ANALYSIS}

\subsection{Methodology}

The use of micro panel data and multi-state stochastic models have led to a paradigm shift in the empirical labor market literature. In particular, individual labor market transitions between different labor market states have now became traceable through Markov chain models ${ }^{5}$. As Fabrizi and

\footnotetext{
${ }^{5}$ For detailed discussion on Markov chain models, see Gourieroux, C. (1989, chapter 5) or the English version translated by Klassen, P. B. (2000, chapter 6).
} 
Mussida (2009: 236) summarize, Markov chain models enable estimating transition probabilities when subjects are observed only at discrete time points, and hence exact transition dates are not available.

A random process $X_{i}$ defined over a discrete state space $\bar{K}=[1, \ldots, K-1]$ is called a first-order discrete Markov chain if

$$
\text { Pr. }\left(X_{i}=k \mid X_{i-1}, \ldots, X_{1}\right)=\operatorname{Pr}\left(X_{!}=k \mid X_{i-1}\right)
$$

If $\bar{X}_{\mathrm{i}}$ is a Markov chain and $j, k \in[K]$, the conditional probability

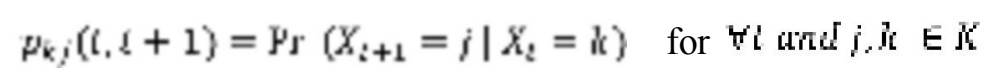

is called the transition probability of moving from state $k$ to $j$ at time $t$. If the transition probabilities are independent of time, Markov chain is time-homogenous ${ }^{6}$, that is

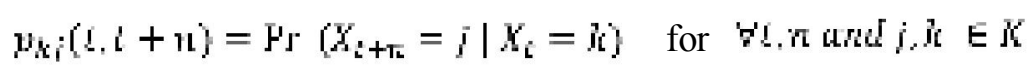

Given a finite set of states $\bar{K}=\{1, \ldots, \bar{K}-1\}$, the transition probabilities can be represented in a discrete time transition probability matrix,

$$
P=\left[\begin{array}{ccc}
p_{\mathrm{oL}} & \cdots & p_{\mathrm{OKK}} \\
\vdots & \ddots & \vdots \\
p_{K 0} & \cdots & p_{\kappa K}
\end{array}\right]
$$

The P matrix can be estimated by the maximum likelihood estimator for $p_{i j}=\frac{N_{k 1}}{n_{k}}$ where $N_{k i}$ is the number of transitions from state $k$ to $j$ and $m_{k}$ is the number of transitions out of state $k$.

For our specific purposes, we consider $X_{\mathrm{i}}$ to denote the labor market state of a given individual at time $t$. We define the state space $K$ to comprise six labor market states; formal salaried (FS), informal salaried (IS), formal self-employed (FSE), informal self-employed (ISE), unemployed (U) and inactive (N). The definitions, as provided above, are adopted to be consistent with the ILO definitions and inclusive for a comprehensive analysis. Along these lines, $\mu_{i i}$ refers to the probability of finding a worker in state $j$ at the end of the period given that the worker was at state $k$ at the begining of the period $^{7}$.

\footnotetext{
${ }^{6}$ For further information, see http://www.math.rutgers.edu/courses/338/coursenotes/chapter5.pdf

${ }^{7}$ As Lehmann and Pignatti (2007) state, these estimates are close to the true transition probabilities in the absence of round-tripping.
} 
In the following analysis, we estimate the P-matrix of raw transition probabilities for 2006-2007, 2006-2008 and 2006-2009. That is, we construct three different P-matrices for one, two and three year transitions. In this way, we are able to compare transition tendencies across different time spans, and hence in a sense test for robustness of the results. Furthermore, given the gravity of the agriculture sector in Turkish labor market, the analysis is conducted seperately for both total and non-agricultural employment.

\subsection{Results}

The first thing to notice in Tables $4 \mathrm{a}, 4 \mathrm{~b}$ and $4 \mathrm{c}$ is that the transition probabilities display a significant level of congruence across the two, three and four year panels. Nevertheless, each case will be discussed below for integrity purposes. Secondly, when agriculture is excluded from the sample, the picture somewhat alters but the changes are mostly limited to Informal self-employed and Inactive categories. Thirdly, the most discernible transition pattern can be observed along the main diagonal of the probability matrix. By definition, $y_{i j}$ reflects the probability that an individual remains in a given state. The high levels of $y_{i j}$ imply that majority of the subjects in each category do not move out of their initial labor market state, except for the unemployed.

From 2006 to 2007, we observe that approximately 90 percent of those who are initially formalsalaried remain in their state. This result is well consistent with the traditional approach which sees labor informality as a survivalist strategy when formal employment opportunities are limited ( $\mathrm{Yu}$, 2009:3) $)^{8}$. Once an individual becomes formal-salaried, he/she is unlikely to leave this state. The almost negligible transitions into other states are typically results of early retirement. When agriculture is excluded, the transition dynamics of the formal-salaried do not alter at all. This finding is a mere reflection of the agriculture being eminently an informal sector.

The informal-salaried, who constitute roughly 10 percent of total employment, demonstrate a higher level of mobility. About 13 percent of those who were employed as informal-salaried in 2006 becomes formal-salaried in 2007. Considering that the reverse transition probability from formal-salaried to informal salaried amounts to only 2.8 percent, this figure is quite noteworthy. This finding indicates that the flows between formal-salaried and informal-salaried are asymmetrical, hence conforms to the conventional one-way flows from informality to informality. Approximately 22 percent of informalsalaried move into non-employed state, either as unemployed or inactive. The transition from informal-salaried to informal self-employed is limited at 7 percent. Exclusion of agricultural employment from the sample appear to have only trivial effects on the transition probabilities of the

\footnotetext{
${ }^{8}$ Fields (1975), Mazumdar (1976), Bernabè (2002), Perry et al. (2007)
} 
informal self-employed. This result evinces that agricultural workers do not figure in informal-salaried state.

The formal self-employed category, which amounts to only 3.5 percent of the sample, does not reveal any significant mobility pattern. The most noticeable flow out of formal self-employed is that into informal self-employed. The underlying dynamics for such a transition tendency will be investigated in the next section. For the non-agricultural sample, formal self-employed display almost the same transition pattern, the only exception being a fall in the probability of transition into informal selfemployed.

The informal self-employed constitute nearly one fifth of the sample labor market. The outflows are limited to 4 percent into informal-salaried, 4.5 percent into formal self-employed, and 13 percent into non-employment states. Transition to formal-salaried state is almost negligible. Altogether, these figures imply that informal self-employed are usually those disadvantaged who face barriers to mobility. As the labor market composition analysis demonstrates, agricultural employment mostly prevails as informal self-employment. Indeed, the sample weight of this state falls from nearly 18 percent to 4 percent when agricultural employment is left out. Needless to say, the most noticeable effects of excluding agriculture are observed on the transition dynamics of this state. In particular, the transition probabilities of flows into all other states double, except for that into inactive state. When agricultural workers, who consititute the majority are left out, informal self-employment emerges as a rather active state. Transition probabilities, albeit change in magnitude, do not alter the ouflow pattern of the informal self-employed. The likelihood of transiting out are, in decreasing order, into inactive, formal self-employed, informal-salaried, unemployed and formal-salaried.

The unemployed are visibly the most mobile among all labor market groups. Nevertheless, they display a rather heterogenous transition pattern. The remainers are limited to only 27.9 percent, whereas flows into formal-salaried prevail at 15.2 percent, informal employment at 32.4 percent and inactive at 23.8 percent. In other words, unemployed have the highest probabilities of transiting into above named states. These findings, overall, are a mere reflection of the heterogeneity of the unemployed category. The only noticeable inference to be drawn is that for unemployed, probability of transition to informal employment is twice of that to formal employment. It follows that formal employment opportunities are limited and have higher entry barriers. By definition unemployed state is irrelevant to exclusion/inclusion of agriculture; thus the transition probabilities are analogous.

Inactives constitute the largest segment of the sample. Outflows, being almost negligible, reflect the rigidity of the inactive transitions. Reluctance to move of inactives can be explained by a number factors such as discouraged workers and women inactivity being the most common. Indeed, the 
incidence of inactive women still stands as a major virtue of the Turkish labor market, thence distorts most aggregate labor market figures. In fact, the inactivity rate stands at 70 percent for women, whereas for men it is only 22 percent. If agriculture sector is excluded, the sample weight of inactives increase by approximately 10 percent. However, the probabilities of transition into other states are almost identical with the former counterparts.

Considering the 2006-2008 panel in Table 4b, we can easily notice that the transition probabilities remain to be more or less the same. The only changes, albeit hardly noticed, are a rise in informalsalaried to formal-salaried transition probability from 12.9 percent to 14.7 percent; a fall in formal self-employed to informal self-employed transition probability from 12 percent to 8.3 percent, and a fall in informal-salaried to informal self-employed transition probability from 7 percent to 5.5 percent. If we further increase time span to comprise 2006-2009 transitions, as Table 4c illustrates the picture is still the same. Along these lines, it can be argued that increasing the time dimension of our panel does not alter the transition patterns in the Turkish labor market.

In addition, no significant effect of the global economic crisis in 2009 on the labor market can be detected. The same conclusions apply when non-agricultural employment is considered.

\section{MULTINOMIAL LOGIT MODELS}

\subsection{Methodology}

Identifying the variables that are related to the probability of worker transitions is of paramount practical and policy-making interest. In order to characterize mobility patterns in more detail, we utilize multinomial logit (MNL) specification to model the labor market transitions. Indeed, MNL model offers a statistically rigorous way to predict the probability of each possible transition as a function of individual characteristics ${ }^{9}$.

Formally, a simple MNL model specifies that:

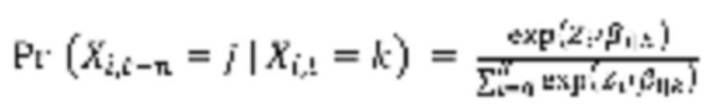

where $Z_{1}$ are case-specific regressors for each individual $i$; $X_{i . \mathrm{L}} \in[0,1,2, \ldots, K]$ is the labor market state of individual $i$ at time $t$. In order for such a MNL model to identifiable, one outcome $k \in \mathbb{K}$ is specified as the base or reference group such that $\beta_{k \mid k:}=0$. Thereafter the parameter vector $\hat{\beta}$ is straightforward to estimate by maximum likelihood estimation (MLE) method. For MNL models,

\footnotetext{
${ }^{9}$ There are a number of specifications for the MNL model. As Bernabè and Stampini (2009) indicate: "dynamic multinomial logit model -see Gong et al. (2004)- is theoretically the most appropriate model which accounts for unobserved heterogeneity. However, the estimation of a dynamic MNL is empirically infeasible for our specific case due to data limitations and sensitivity". 
however, $\hat{\rho}$ coefficients are seldom used for inference ${ }^{10}$. Instead, marginal effects of the independent variables are computed as ${ }^{11}$ :

$$
\frac{\partial \operatorname{Pr}\left\{X_{1}=j\right)}{\partial y_{\mathrm{a}}}=\operatorname{Pr}\left(X_{i}=j \mid Z\right) \cdot\left[\beta_{1 n}^{i}-\sum_{i=0}^{K} \beta_{\mathrm{m} 2}^{j} \operatorname{Pr}\left(X_{i}=j|Z\rangle\right]\right.
$$

In this study, we modify the above MNL methodology to be compatible with our specific purposes and comparable to the existing studies on other countries. We estimate six simple multinomial logit regressions for each labor market state of departure, namely formal-salaried, informal-salaried, formal self-employed, informal self-employed, unemployed and inactive. For robustness check purposes, this analysis is repeated for all three samples (i.e. 2006-2007, 2006-2008 and 2006-2009 panels) as was done in the transition analysis section. To this end, dependent variable in each regression conveys a different interpretation. It is defined as a categorical variable which takes the value 0 if the individual maintains his/her labor market state from 2006 to $2007^{12}$. Whereas for each of the five possible outflows, values from 1 to 5 are assigned. Consider the subsample of individuals who were employed as formal-salaried in 2006. The dependent variable takes the value "0" if the individual remained as formal-salaried in 2007. If the individual changed state in 2007, the dependent variable assumes values from 1 to 5 for transitions into informal-salaried, formal self-employed, informal self-employed, unemployed and inactive states, respectively.

The explanatory variables include demographic characteristics of the individual in 2006 (gender, age, education level, marital status) and employment characteristics of the individual (occupation, sector of economic activity, firm size, work tenure, work tenure squared). A comprehensive table of variable definitions is provided in Appendix (Table A1). Note that for the unemployed and inactive employment characteristics cannot be used as explanatory variables, hence are kept out of the regressions.

The transition analysis has shown that our evidence does not change on a large scale if agricultural workers are excluded from the sample. The only notable differences in mobility patterns are observed for informal self-employed, as they are mostly employed in agriculture. As discussed in the previous section, when agricultural workers are removed we find that mobility of out of the informal selfemployment increases and that into informal self-employment decreases to a notable extent. The probability of remaining in informal self-employment decreases by almost 15 percent. Similar results are observed to hold for male and female only samples. This pattern, overall, indicates that agricultural

\footnotetext{
${ }^{10}$ As Greene (2002:722) states, the parameters of the multinomial logit model do not have a direct intuitive interpretation in regards to their sign or magnitude. Their use for drawing statistical inference in empirical research is uncommon.

${ }_{11}^{11}$ The time subscript ( $\mathrm{t}$ and $\mathrm{n}$ ) is omitted for expositional convenience.

${ }^{12}$ For presentation brevity, the variable definitions are given for 2006-2007 panel only. Same definitions apply when 2007 is replaced with 2008 and 2009, for the 2006-2008 and 2006-2009 panels respectively.
} 
has a very low level of mobility into other labor market states. In the following analysis, we estimate separate regression for total and non-agricultural samples considering robustness purposes, but only discuss the results of total sample regressions ${ }^{13}$.

Multinomial logit regressions are estimated by Maximum Likelihood Estimation (MLE). The marginal effects are computed at the means of the explanatory variables. All empirical analyses are done with STATA version 10 .

\subsection{Estimation Results}

This section discusses the results of the multinomial logit regressions in order to identify the influence of individual characteristics on worker transitions with a special emphasis on informal/formal divide, thereby shed some light on the dynamics of the Turkish labor market. The multinomial logit analysis is conducted for each set of panel individually to check for robustness and variation of the results ${ }^{14}$. For each panel data set, we estimate six MNL regressions based on the state of departure (i.e. formalsalaried, informal-salaried, formal self-employed, informal self-employed, unemployed and inactive). The marginal effects for 2006-2007, 2006-2008 and 2006-2009 panel data are reported through Tables $5 \mathrm{a}, 5 \mathrm{~b}$ and $5 \mathrm{c}$ respectively. The presentation adopts the standard multinomial logit regression interpretation within the following framework: The marginal effects depict "how the given explanatory variables influence the probability of leaving the initial state for a certain destination state relative to the probability of no outflow" (Bukowski, 2005: 16). Overall, we find that multinomial logit evidence corroborates the previous transitional analysis to a remarkable extent.

\subsubsection{Transitions from Formal-Salaried State}

In this subsection we examine 2006-2007 transitions out of formal-salaried state. MNL results appear to provide significant insight into the observed outflows. For this particular case, coefficient estimates represent the impact of explanatory variables on the probability of leaving formal-salaried state for a certain destination relative to the probability of no outflow. In this framework, gender is clearly ascertained to play a powerful role in explaining mobility out of the formal-salaried state. In particular, formal-salaried women are significantly less likely than men to become informal-salaried. Likewise, being female decreases the likelihood of transitions into formal self-employment, ceteris paribus. Considering the fact that only less than one percent of the women in our sample are formal selfemployed (see Table 3), the highly significant negative coefficient comes by no surprise. On the contrary, the effect of this variable becomes significantly positive for probability of moving into inactivity. Indeed, this result is consistent with our earlier finding that almost 70 percent of sample

\footnotetext{
${ }^{13}$ For presentational brevity the multinomial logit regression results for the non-agricultural sample are not reported, but available upon request.

${ }^{14}$ In following the same vein as the Transition analysis in Section 4, we consider transitions for 2006 to 2007,2006 to 2008 and 2006 to 2009, separately.
} 
women are inactive (see Table 3). The high level of inactivity of women seems to dominate their transition patterns. Given the traditional division of gender roles and family responsibility of women in Turkey, women are notably under-represented in formal employment. Apparently, if and/or once they become formal-salaried, they are more persistent in this state compared to men. Notwithstanding, the estimation results indicate statistically significant differences among transition patterns of women at different age groups. Accordingly, formal-salaried women aged 15-24 are less likely than those aged 25-44 to move into informal-salaried and formal self-employed states. It is noteworthy to mention at this point that the prime working age in Turkey is between 25-44, which corresponds to the age when families are started and children are born. In this context, middle age women tend to have stronger incentives (i.e. household financial needs) for working and/or re-employment in case of a layoff. Almost identical observations seem to hold with respect to results for 2006-2008 and 2006-2009 panels. Along these lines, we can conclude that gender remains a robust and powerful predictor of transitions out of formal-salaried state.

Regarding age, we find that formal-salaried workers aged 25-44 and/or 45-64 are significantly less likely to become informal salaried, compared to the reference category of age 15-24. This finding may be the reflection of two facts. First, as mentioned by Huitfeldt (1998:24), young individuals have a higher probability of moving out of employment. Second, young and less experienced workers often experience entry barriers to formal-salaried employment. Given that only about seven percent of aged 15-24 are formal-salaried ${ }^{15}$, it is no surprise that they are the least likely age group to maintain their state. One noteworthy finding is associated with transitions into inactivity. Compared to workers who are formal-salaried in 2006 and aged 15-24, the probability of dropping out of labor force is lower for 25-44 age group, but higher for 45-64 age group. This finding can be interpreted in two ways. First, young adults are often the first to be affected in case of a layoff. Yet, they are more flexible in remaining inactive compared to middle aged workers who often cannot afford to drop out of labor force. Whereas, retirement is probably the main reason behind older individuals' displaying a higher probability of transition into inactivity. The effects of age on the transitions of formal-salaried individuals are robust to 2006-2008 and 2006-2009 panels as well, thereby confirming its explanatory power.

Household demographic structure seems to play only negligible roles in explaining transitions of the formal-salaried workers. The marginal effect of marriage on outflows is only slightly significant for flows into formal self-employment and inactivity states. In particular, married formal-salaried are significantly more likely to become formal self-employed, but less likely to drop out of the labor force compared to the singles. This evidence points to the spouse effect in one's employment choice. As for

\footnotetext{
${ }^{15}$ See Table 3.
} 
female-marital status interaction, we find a strongly negative effect of married women on outflows into informal-salaried and/or formal self-employed, and a positive effect on transitions into inactivity. Having/not having children turns out to have almost no statistically significant explanatory power for formal-salaried workers' mobility patterns. Turning to the household size, estimation results indicate a significantly negative effect only for transitions into formal self-employment and inactivity. That is, the larger the household size the lower the probability of leaving formal-salaried employment and becoming formal self-employed and/or inactive. These findings, overall, point to the traditional family influence on individual labor decisions as increased family responsibility, increased dependence on safe employment and higher motivation for re-employment in case of a lay-off. Turning to 2006-2008 transitions, marital status becomes insignificant for all outflows, though coefficients signs remain as same. The marginal effect of household size appears still significantly negative for outflows into formal self-employment, but becomes insignificant for explaining outflows into inactivity. Esimation results for 2006-2009 transitions also do not reveal a remarkable difference. The effect of being married on transitions into inactivity continues to be significantly negative, but that to formal selfemployment now becomes positive albeit insignificant. We prefer not to treat the reverse in sign as meaningful, but a statistical outcome.

In line with the conventional wisdom, high school and university degree significantly reduce the probabilities of every movement out of formal-salaried. This pattern may be explained as purely result of formal-salaried jobs being intrinsically more stable as argued by Pages and Stampini (2009:398). However, there usually exist other underlying facts. First, as Maloney (1999: 292) suggests, the opportunity cost of working informally is considered to be lower for low-skilled individuals, especially for those who usually have only minimal earnings in formal sector. Second, the risk of being subject to involuntary layoffs is usually lower for better-educated workers. Even in case of a layoff they are often more likely than less-educated workers to find another formal-salaried job. Moreover, as suggested by Gong et al. (2004:17) "These effects may, however, also be demand-side driven, reflecting different educational requirements in the two sectors, with the formal sector jobs typically requiring more (formal) education than the informal sector jobs". Taking the evidence on education altogether suggests that labour market transition probabilities are partly determined by prior educational attainment. Considering the estimation results for the three and four year panels of 20062008 and 2006-2009, we find the explanatory power of education to be increased. The coefficient of no education now becomes singificant for transitions into informal self-employment, inactivity for 2006-2008 panel, and those into informal-salaried and unemployment for 2006-2009 panel. In other words, individuals with no education seem to be more persistent in formal-salaried state compared to the primary school graduates. These confutative results appear to contradict the basic premises of established theory. Given that only about one percent of formal-salaried have no education, the coefficients are regarded as of doubtful validity and vain. Coefficient for secondary school becomes 
significant for explaining outflows into informal-salaried state if we increase the time span of the panel. This evidence is consistent with earlier arguments that as the level of education rises, one is more likely to remain in formal employment. Formal-salaried workers with secondary school degree are also found to be significantly less likely to become unemployed and/or inactive compared to primary school graduates, which again confirms the basic premises. The influence of higher education exhibit almost identical patterns for three and four year panels, thereby underlining its explanatory power.

The MNL results reveal that experience, measured by total years of employment, does not seem to significantly explain any transition out of formal-salaried state, except for those into inactivity. Accordingly, probability of moving into inactivity relative to remaining in formal-salaried state significantly decreases with work experience. As is well-established in literature, the higher the experience, the lower the effect of negative labor shocks on a worker. Therefore, it is often easier for more experienced workers to maintain labor market state and/or achieve a match between jobs and personal attributes in case of a layoff. Considering 2006-2008 and 2006-2009 transitions out of formal-salaried state, the signs of experience and experience squared, though remain the same, are not statistically significant. The only exception is the negative coefficient of experience for transitions into unemployment which becomes significant for 2006-2008 panel. Overall, estimation results indicate that experience may not be a powerful explanatory variable, which can be interpreted twofold: First, formal-salaried workers in Turkey are mostly employed in public sector, and public jobs often offer life-time employment. If one ever becomes formal-salaried, which usually happens in the early ages, he/she is quite unlikely to exchange it for another type of employment or be subject to lay-off. In this regard, experience does not exert a determinate effect on their mobility patterns.

Sector of economic activity appears to play a fairly significant role in explaining movements out of formal-salaried state. Compared to the base category of industrial workers, services workers are significantly less likely to move to informal-salaried, unemployed and inactive states. In other words, industrial workers display a somewhat stronger persistence in formal-salaried employment relative to the services sector workers. The result is coherent with the fact that about 70 percent of industrial workers are indeed formal-salaried. The coefficient of agriculture appears to be significantly negative for all flows out of formal-salaried state. However, considering the share of formal-salaried in agriculture is only less than one percent, we prefer not to make any conclusive statement regarding the effects of agriculture. Construction sector is associated with a significantly lower probability of formal-salaried to formal self-employment transition relative to industry sector. Overall, a closer look at the sectoral breakdown of labor market transitions highlights the importance of sector's nature in affecting mobility tendencies, and evinces that some sectors are intrinsically more stable than others. Sector coefficients somewhat alter in terms of either size, magnitude or significance if we consider 
three and four year panels, namely 2006-2008 and 2006-2009. We will briefly discuss the differences which we find to be notable and indicative. First, coefficients of agriculture appear to switch signs and become positive for outflows into informal self-employment. Though not found as significant, this effect seems more consistent with the existing theory and evidence. As reported in Table 3, over 80 percent of agricultural workers in our sample are detected to be informal self-employment. That being said, we would typically expect the likelihood of transitions from formal-salaried to informal selfemployment to be higher for the agricultural workers compared to the industrial workers. A similar result holds for the construction sector, which exhibits a negative sign for 2006-2007 transition, but becomes significantly positive for 2006-2008 and 2006-2009 outflows into informal-salaried state. Given that approximately 60-70 percent of construction workers are employed as informal-salaried, they are typically expected to display a higher probability to move into informal-salaried state compared to industry workers. The coefficient of services, though still negative, becomes insignificant for outflows into informal-salaried when we consider 2006-2008 and 2006-2009 transitions. Nevertheless, given that over 50 percent of services workers and approximately 70 percent of industry workers are formal-salaried the coefficient is not expected to provide a determinate effect.

The lens of firm size variable, confirming our priors, offers a powerful tool for understanding the transitions out of formal-salaried state. In particular, workers in firms of size 50 or more are strongly less likely than those in firms of size less than 10 to leave formal-salaried employment, and move to any other labor market state. Considering the fact that more than 90 percent of large firm employment is associated with formal-salaried state, this finding comes by no surprise. Whereas firm size 11-49 turns out as statistically significantly negative for only outflows into informal-salaried and formal selfemployed groups. The results confirm the universally accepted stylized fact that informality declines sharply by increasing firm size. Taymaz (2010: 31) attributes this fact to "the probability of enforcements (large firms are more likely to be identified and inspected by the authorities), and productivity differentials since small firms are, on average, less productivity and thus has a stronger incentive to operate informally to reduce the cost of compliance". Firm size appears to display the similar effects when we consider estimation results for 2006-2008 and/or 2006-2009 transitions, reflecting the fact that its a pretty powerful predictor of formal-salaried workers' mobility.

\subsubsection{Transitions from Informal-Salaried State}

This section of the paper aims to explore the underlying dynamics of transitions out of informalsalaried state. The coefficients of the multinomial regression represent the marginal effect of a given explanatory variable on the probability of moving into any given labor market state relative to remaining in the informal-salaried state.

Plentiful evidence exists for the differential impacts of gender on transition patterns of informal- 
salaried individuals. Women are significantly less likely than men to leave informal-salaried employment and move to either formal or informal self-employment. This finding points to women being more settled in informal-salaried positions, and less likely to consider leaving and and becoming self-employed. Whereas, they display a significantly higher probability of dropping out of the labor force as compared to men. As Cook et al. (2010) report, women are often disproportionately pushed out of salaried (i.e. formal and/or informal) employment, and are disadvantaged compared to men for new employment opportunities in the labour market given equal qualifications. Notwithstanding, the reproductive role of women and traditional gender division of labor in family structure in Turkey are often the most important underlying causes. Turning to estimation results for 2006-2008 and 20062009 transitions, female variable seems to remain robust. When combined with its high significance level, this finding suggests that gender is indeed a powerful variable explaining mobility patterns of informal-salaried workers, particularly flows into self-employment and inactivity.

In the context of transitions out of informal-salaried state, age variable has almost no statistically significant explanatory power. The only remarkable age effect prevails for outflows to inactivity. Compared to the 15-24 age group, individuals aged 45-64 are more likely to perform a transition into inactivity rather than remaining in informal-salaried state. The same results hold when we consider the female-age interaction variables. Turkey's early and gender differentiated retirement policy and pension system are the primary reasons for such a pattern. Especially elderly women, either retired or laid off, find it comparatively harder to find new employment, hence become inactive. Turning to the 2006-2008 panel, we notice that informal-salaried workers aged 45-64 are significantly less likely to become formal-salaried. This finding is consistent with the fact that public sector accounts for a large share of formal-salaried employment, and that public sector jobs are often acquired during early ages. Moreover, generous pension schemes have resulted in an epidemic of early retirement, after which elder individuals often move into other types of employment or inactivity. Overall, age remains to be insignificant in explaining informal-salaried workers' transitions for the three and four year panel specifications as well. The disparities in estimation results are barely discernible.

It is interesting to note that marital status and children has no statistically significant relationship with any type of informal-salaried mobility. Household size, on the other hand, appears to somewhat explain transitions into informal self-employment, unemployment and inactivity. Considering the highly significant coefficient of hsize for all given outflows, we can readily assert that the probability of remaining in informal-salaried employment increases with the household size. Clearly, this result stems from increased responsibility and financial needs coming with increased household size. As for the 2006-2008 and 2006-2009 multinomial logit results, we observe that same conclusions apply with respect to the effects of household characteristics on mobility of informal-salaried workers. 
As regards the education level and in line with the conventional wisdom, university graduates appear as significantly more likely than primary school graduates to move into formal-salaried state rather than remaining as informal-salaried. Moreover, the likelihood of flows into formal self-employment is significantly lower for uneducated and/or university graduates relative to the reference group of primary school graduates. We also find evidence that secondary school graduates are less likely to become inactive relative to primary school graduates. While interpreting results, we should account for the fact that primary school graduates dominate all labor market states with the highest share, and make up about 50 percent of the labor force. Nevertheless, evidence appears to be in line with the existing theory and conventional wisdom that formality increases with education. For 2006-2008 and 2006-2009 transitions, the most notable disparity is observed for individuals without any education. First, uneducated informal-salaried workers become significantly less likely than primary school graduates to move into informal-salaried employment. Given that share of formal-salaried employment is only 2 percent for uneducated individuals compared to 13 percent for primary school graduates, the result confirms our expectations. Second, the sign of no education swiches from positive to negative for outflows into unemployment, and becomes significant for 2006-2009 estimation. This difference is deemed to be associated with the effects of economic crisis. Third, secondary school graduates become significantly more likely than primary school graduates to remain in informal-salaried when we increase time dimension of the panel. This result is nothing but typical given our basic premises.

Experience appears to be the most significant determinant of the outflows of informal-salaried workers. As experience increases, the likelihood of switching out of informal-salaried state to all other labor market states significantly falls. That is, the higher the experience, the higher the probability that an individual persists in informal-salaried state. This finding is consistent with the view pointed out by Galli and Kucera (2003:4) and several studies, that returns to experience are often higher in informal employment ${ }^{16}$. The most discernible difference between 2006-2007 and other panels concerns work experience. In fact, coefficient of experience seems to lose almost all of its explanatory power, albeit having the same signs.

The multinomial logit coefficient estimates for economic sector imply that workers in agriculture, services and construction sectors are all significantly less likely to become formal-salaried than industrial workers. As Table 3 depicts, the share of formal-salaried employment in industry sector is approximately 70 percent. The evidence taken together, point to the intrinsically formal nature of

\footnotetext{
16 “See Funkhouser (1996) for El Salvador, Guatemala, Honduras, Nicaragua and Costa Rica; Funkhouser (1997) for El Salvador; and Marcouiller et al. (1997) for El Salvador, Mexico and Peru for examples. Related evidence is found in two other studies. Telles (1993) finds higher returns to experience for both male and female unprotected workers (self-employed and employees) than for self-employed protected by social security in Brazil; and Mohan (1986) finds higher returns to experience for male self-employed workers than for blue-collar and white-collar employees in Colombia" (Galli and Kucera, 2003:4).
} 
industry. If one leaves informal-salaried state for formal-salaried, he/she is often employed in industry sector. Similarly, informal-salaried workers in construction and services sectors display a lower probability of transition into formal self-employed state, compared to industrial workers. Moreover, we find evidence that probability of transition into informal self-employment is significantly lower for construction sector workers, which can be attributed to the intrinsic salaried nature of construction sector. Lastly, informal-salaried workers in services sector are less apt to become inactive compared to workers in industry sector. Comparing and contrasting three sets of panels, we do not detect a marked disparity. Nevertheless, in order to scrutinize underlying dynamics, we have run intersectoral transition analysis individually for 2006-2007, 2007-2008 and 2008-2009 ${ }^{17}$. Except for construction workers who recorded the highest outflow rate overall from 2008 to 2009, transition probabilities are somewhat similar implying that Turkish labor market exhibits a fairly static structure in terms of intersectoral mobility.

In line with the conventional literature and also our previous findings, there is a clear firm size influence. As firm size increases the probability of informal-salaried moving to formal-salaried state rises. Similar results hold for the corresponding variables in the 2006-2008 and 2006-2009 transitions.

\subsubsection{Transitions from Formal Self-Employed State}

The discussion on the transitions of formal self-employed will deliberately be kept brief, since the share of formal self-employed in the sample is only minimal. We only present estimation results but refrain from conclusive interpretations. Also, estimation results for 2006-2008 and 2006-2009 transitions will not be discussed, since the number of observations becomes more than halved thereby renders interpretations of estimation statistics muddled at best and erroneous at worst.

The most evident explanatory factor in transitions out of formal self-employed state appears to be gender. The coefficient of female dummy, albeit being significant for all outflows, should be approached with caution. Since the female share of formal self-employment accounts for less than one percent of the sample, the marginal effects may be artificially high.

Multinomial regression results mark a number of relationships between individual characteristics and probability of flows out of formal self-employment. First, middle aged individuals (those between 25 to 44) are less likely to switch to informal-salaried state compared to the base age group of 15-24. Furthermore, 25-44 aged formal self-employed are strongly less likely to become non-employed (unemployed and/or inactive) compared to the young. These findings represent a very lucid pattern of Turkish labor markets. As can be observed in summary statistics in Table 3, formal self-employment

\footnotetext{
${ }^{17}$ See Appendix Table A2.
} 
in Turkey is mostly a middle age and male phenomena, which mostly corresponds to voluntary or upper-tier self-employment as put by Perry et al. (2007). On the other hand, informal self-employment displays a rather equal distribution across age and gender groups. Furthermore, it comprises almost all unpaid family worker. When combined, it would not be wrong to conclude that informal selfemployment in Turkey pertains rather to an involuntary or lower-tier self-employment type. Regarding female-age interaction effect, we find evidence that females aged 25-44 are significantly more likely than those aged 15-24 to perform a transition from formal into informal self-employment states. On the other hand, female aged 45-64 display a higher probability of maintaining formal selfemployment rather than moving into formal- and/or informal-salaried employment, compared to female aged 15-24. Whereas the effect is reversed for transitions into inactivity.

With respect to the effects of education on the relative probability of moving out of formal selfemployment relative to remaining, we find that outflows into formal- and informal-salaried employment is significantly lower for the none educated individuals compared to those with primary school diploma. The reverse is true for transitions to unemployment that is, non-educated are more likely to become unemployed compared to primary school graduates. For higher education variables, university degree appears significantly negative for transitions to informal self-employment, unemployment and inactivity. Secondary school graduates exhibit a 35 percent reduction in the probability of transition out of formal self-employment into unemployment.

The likelihood of outflows to informal self-employment and unemployment are significantly lower for married, hence they appear to be more persistent in formal self-employment compared to singles. Though household size does not have a significant effect on any outflow; having children seems to be significantly negative at 5 percent for transitions to unemployment.

As for sector of economic activity, industry workers form our reference category. An interesting result is that agricultural formal self-employed are significantly less likely to become non-employed compared to industry workers. For construction workers the probabilities of transition to informalsalaried, informal self-employed and inactive states rather than maintaining formal self-employment are significantly lower. Considering the fact that construction workers are only about one percent formal self-employed, the estimation results are not very conclusive. The odds of being unemployed is lower for services workers.

\subsubsection{Transitions from Informal Self-Employment State}

Informal self-employment accounts for the second largest state in our sample after inactives. The decomposition analysis depicts that majority of informal self-employment is female, low skill and 
works in agriculture sector. Combined with these findings illustrated in Table 3, multinomial logit evidence provides further insight to mobility dynamics of informal self-employed workers.

Female dummy is statistically significant for all the outflows from informal self-employment. In particular, informal self-employed women exhibit a higher probability to move into inactivity, but a lower probability to move into all other states. Put differently, they are more persistent in informal self-employment than men. Considering the fact that share of informal self-employment in male and female samples are almost identical and more than half of female workers in our sample are employed as informal self-employed, the results are of great interest. When we increase the time dimension of our panel and consider 2006-2008 and 2006-2009 flows, female dummy somewhat loses much of its explanatory power except for transitions into inactivity which remains robust. Particularly notable is the change of sign for transitions to unemployment, as informal self-employed women now exhibit a greater likelihood of becoming unemployed as opposed to their male counterparts. Though not found to be statistically significant, we consider a positive sign as more accurate. This finding, in fact, is a mere reflection of the entry barriers faced by women. The robust effect of gender on transitions into inactivity is nothing but the manifestation of the magnitude of inactivity among women.

Age does not have a notable explanatory power in informal self-employment mobility patterns. We only find evidence that transitions from informal self-employment to inactivity decreases for 25-44 age group, but increases for 45-64 age group, compared to base age group of 15-24. Additionally, probability of becoming unemployed compared to remaining in informal self-employment is found to be lower for elder individuals. The findings are identical for 2006-2008 and 2006-2009 transitions as well.

Education has virtually no role in explaining mobility of informal self-employment for 2006-2007 transitions. Whereas if we consider three and four year transitions for 2006-2008 and 2006-2009, the picture changes albeit slightly. First, in conformity with the traditional theory, those informal selfemployed with no education are found to be highly less likely than primary school graduates to become formal salaried for 2006-2009 logit results. Moreover, coefficient of university degree becomes highly significantly negative for moving to unemployment for both three and four year panels. Third, we find some evidence that if education level increases likelihood of moving from informal self-employment to informal-salaried employment significantly falls. This result denotes that education, hence skill level of informal self-employed are on the average lower than that of informalsalaried workers.

Experience, on the other hand, is only significant for transitions out of informal self-employment into inactivity. In particular, individuals with more work experience exhibit a lower probability of 
becoming inactive compared to remaining in informal self-employment. The effect is robust for all panel specifications.

In the analysis of transition out of informal self-employment, we trace significant sectoral effects. First, informal sef-employed agricultural workers exhibit significantly lower probabilities for all transitions out of informal self-employment compared to that of informal self-employed industry workers. This finding is most likely a statistical artifact resulting from 80 percent of informal selfemployment being in agriculture but only about 5 percent in industry. Another interpretation would be that informal self-employment is a far more unstable labor market state where entry and exit are easier. Similarly, services workers are found to be negatively associated with all outflows, thereby significantly more persistent in informal self-employment compared to industry workers. However, the statistical results should arguably be approached with some caution considering that share of informal self-employment in industry sector is only trivial. For 2006-2008 and 2006-2009 transitions, almost identical findings are reported except for construction workers now being significantly far less likely than industry workers to move into formal-salaried state.

\subsubsection{Transitions from Unemployment}

In this section, we focus on the determinants of outflows from unemployment. Confirming our priors, we find that unemployed women are seemingly less likely than men to find employment, but more likely to become inactive. The effect of female dummy is negative (positive) particularly significant for outflows into formal and informal self-employments (inactivity). These results are in agreement with two salient gender-specific characteristics of the Turkish labor market: women are at a notable disadvantage to get a job, and/or less encouraged about wanting a job, thereby making fewer efforts to find work. However, due to data limitations and presentational brevity, we are not able to further scrutinize the gender gaps in the mobility patterns of unemployed. With regards to three and four year transition analysis, particularly noteworthy is the significantly positive female coefficients for outflows into both formal and informal-salaried employments in 2006-2008 logit results. This result is most likely just a statistical error.

Age also appears to play a notable role in explaining mobility of the unemployed individuals. Odds of transition out of unemployment into formal-salaried, informal-salaried and inactive states are significantly lower for middle aged compared to the youth. Similarly, the coefficients of 45-64 age dummy is observed to be significantly negative for outflows into formal-salaried, informal-salaried and formal self-employment. This finding demonstrates the persistence of the elderly in unemployment compared to the base age category of $15-24$, who are somewhat more likely to find either salaried and/or self-employment jobs. More interesting are the coefficients of female-age interaction dummies. In particular, women of age 45-64 exhibit a significantly lower probability of 
finding a formal-salaried and/or informal self-employment position (i.e. leaving unemployment state) in relation to women of age 15-24. On the contrary, they are significantly more likely to become formal self-employed rather than remain unemployed. When combined, reported coefficients imply that the young somewhat find it easier to move from unemployment into employment, which may be explained by their eagerness to find a job, lack of entry barriers into employment or employers being more favorably disposed toward employing younger workers. Age loses much of its explanatory power in mobility of the unemployed when we consider 2006-2008 and 2006-2009 transitions. The only robust effect is the 45-64 aged unemployed being significantly less likely than the 15-24 aged group in moving to formal-salaried employment, thereby confirms the characteristic of Turkish labor market whereby formal-salaried employment is mostly attained in early ages of working life.

Marital status and having/not having children do not exhibit any significant influence on outflows from unemployment. Household size, albeit being only weakly significant, is negatively related to finding formal and/or informal self-employment. Put differently, as household size increases one is less likely to prefer self-employment to unemployment. This may be the result of added worker effect, that is if other members of the household are employed one has less incentives to find a job. Therefore, he/she can remain as unemployed for a longer time. Needless to say, the larger the household size, the greater the added workers effect. Three and four year panels do not reveal any significant mobility patterns regarding the household demographics. Combined with the fact that the one and only statistically significant household variable, hsize, is merely significant, we may conclude that household demographics do not exert a notable influence in the mobility of the informal self-employed individuals.

With respect to education, we find that chances of finding a formal-salaried job out of unemployment state significantly increases for high school and university graduates compared to primary school graduates. The estimation results indicate that the coefficient of no education and secondary school dummies are statistically significant for transitions into formal self-employment. However, we prefer to view these coefficients with skepticism, since the share of formal self-employment is almost negligible for these two education groups. The estimation results for 2006-2008 and 2006-2009 transitions reveal more or less the same mobility patterns. Overall, the age effects confirm the conventional theory which presumes that the duration of unemployment is usually lower for individuals with higher level of education.

Experience appears to be negatively related to the probability of giving up on job searching and dropping out of the labor force, although the significance is weak. This finding may be interpreted in the sense that more experienced workers are often more encouraged to find employment compared to those with less experience, or that having experience enables them to find a job more easily than less 
experienced individuals. Almost identical results are reported for 2006-2008 and 2006-2009 transitions.

\subsubsection{Transitions from Inactivity}

High levels of inactivity, which account for more than 45 percent of our sample, have been a longstanding incidence in Turkish labor markets. However, as decomposition analysis reveals labor force detachment phenomenon is predominantly a product of female inactivity. Multinomial evidence indeed confirms this fact, as women are found to have significantly lower probabilities for all outflows which implies higher persistence of inactivity. Simply put, women are voluntarily opting out of the labor force. The low level of female labor force participation rate can be explained by several structural determinants ${ }^{18}$. Moreover, gender effect on mobility of inactives are markedly robust for the 2006-2008 and 2006-2009 transitions.

We detect age to be a highly significant determinant of transition probabilities pertaining to inactivity. In particular, individuals middle aged and elderly individuals are significantly less likely to move out of inactivity than the reference group 15-24. The age effects are robust for the 2006-2008 and 20062009 transitions. As contended by ILO (2010; p.19) there is a strong decrease of labor force participation among youth since "many more youth now have the choice to stay in education rather than enter the labour market". Whereas, labor force participation rate are often higher for higher age bands of 25-44 and 45-64 years. Turning to female-age interaction effect, the results are mixed. First, females aged 25-44 are significantly more likely to become informal self-employed rather than remain out of labor force. Second, females aged 45-64 are found to be positively associated with outflows into formal-salaried and informal self-employed states, but negatively associated with transitions into formal self-employment instead of staying inactive.

Marital status, although weakly significant, exhibits a positive relationship with movements out of inactivity into employment. The evidence is most likely the result of increased household financial burden and welfare responsibilities. Therefore, one is more motivated to leave inactivity and look for employment opportunities. The result is also confirmed by the significantly negative coefficient of household size for transitions into unemployed. Put differently, the larger the household size, the greater is the likelihood of entering the labor force and searching for work.

Regarding the influence of education on the probability of leaving inactivity, estimation results reveal a somewhat ambivalent picture. Overall, we find that as level of education increases the likelihood of

\footnotetext{
${ }^{18}$ ILO (2010) lists key factors underlying low female labor force participation as religious, cultural and social norms, access to education; fertility; income level; institutions (legal framework, enterprises, labour unions, etc.); sectoral base of the economy (agricultural, industrial or service-based)
} 
leaving inactivity significantly decreases. In particular, secondary school dummy is significant for transitions into informal employment, both salaried and self. High school graduate inactives are less likely than primary school graduates to move into informal-salaried, formal self-employment and informal self-employment states. Almost similar results hold for individuals with a university degree.

\section{CONCLUDING REMARKS}

Research on informal employment in Turkey has been confined only to aggregate and static statistics due to data limitations. Recently, TurkStat has introduced a nationally-representative and rich panel data set from the Income and Living Conditions Survey (SILC) which enables more thorough analysis of labor market dynamics. In this paper, we examine the mobility in the Turkish labor market with a specific emphasis on informality by using the Income and Living Conditions Survey panel data for the period between 2006 and 2009. In particular, we aim to verify to what extent the Turkish evidence confirms the conventional labor market segmentation theory and to characterize the labor mobility patterns and their underlying dynamics. In this regard, we first compute the Markov transition probabilities of individuals moving across the labor market states of formal-salaried, informal-salaried, formal self-employed, informal self-employed, unemployed and inactive. The transition analysis is conducted separately for both total and non-agricultural samples, considering the fact that agriculture sector, being almost 90 percent informal in Turkey, may conceal some important facts. The most evident aspect of the Turkish labor market during the given period is that inactives clearly dominate the labor force. Combined with female labor force being almost 70 percent inactive, labor market dynamics are apparently driven by these two main factors. Nonetheless, transition probabilities display most of the characteristics peculiar to the Turkish labor market. Having computed the P-matrix of raw transition probabilities separately for 2006-2007, 2006-2008 and 2006-2009, we identify that the transition probabilities are almost identical. The most discernible pattern is that most individuals remain in their initial state, except for the unemployed, implying a pretty static structure. The formalsalaried individuals turn out to be the most reluctant to leave their state, confirming the traditional theory which sees formal employment as the ultimate desirable labor market state. The informalsalaried, on the other hand, demonstrate a higher level of mobility than the formal-salaried. The probability of transition from informal-salaried to formal-salaried is about 5 times of the probability of reverse transition, hence conforms to the conventional theory asserting one-way flows from informality to formality. Regarding the mobility patterns of informal self-employed individuals, the outflows are fairly limited which may imply that the state is more like a lower-tier self-employment. However, the exclusion of agriculture changes the picture to a remarkable extent. In particular, the transition probabilities of flows into all other states double, except for that into the inactive state. The unemployed appear as the most mobile among all labor market groups and display a heterogenous transition pattern. A noteworthy finding is that probability of transition from unemployment to informal employment is almost twice of that to formal employment when we consider 2006-2007 
panel. This result also depicts that formal employment opportunities are limited and have higher entry barriers. Inactives, who constitute the largest share of the labor force, exhibits almost negligible outflows indicating the rigid nature of the state. The result is mostly explained by discouraged worker effects and women deliberately preferring to remain out of the labor market.

Next, we conducted multinomial logit regressions individually for each set of panel to identify the impact of individual characteristics underlying worker transitions. The logit analysis is of remarkable importance for designing policy to address labor informality and reduce its negative externalities. Gender evinces to be the most significant determinant of labor flows. Our findings clearly support the view that female are significantly disadvantaged in terms of labor market mobility. Particularly evident is that they are mostly either informal self-employed or inactive, and display relatively lower probabilities of transition into other types of employment. This fact can be explained by several intrinsic factors including the traditional division of gender roles and family responsibility in the household, their reproductive role, negative discrimination against women in hires and lay-offs and their lower average level of education. Following these lines, policy makers should first address the female labor force in order to reduce informality. Increasing their participation rate through positive discrimination tools and policies might alter the informality patterns drastically. Furthermore, investing in education, which turns out to be strongly negatively related to informality, may increase women's chances of finding formal employment.

Another key factor explaining labor market transition patterns is education. In line with the conventional wisdom, high school and university degrees appear to significantly reduce the probability of transition into informal employment. The level of entry barriers and risk of being subject to involuntary layoffs are usually lower for better-educated workers. Also, they display a higher probability of moving into formal employment as compared to the less-educated individuals. Evidently, policy makers may aim at increasing the level of education, hence skills of the overall labor force in order to alleviate labor informality problem.

The intrinsic demographics associated with individual and household characteristics are also found to diplay notable relationships with labor market transitions. Regarding age, we find that the young often experience entry barriers to formal employment, which confirms to the traditional theory. The generous pension schemes resulting in an epidemic of early retirement, is also another significant determinant of mobility patterns in Turkey, which can readily be observed from the statistically significant effects of 45-64 age dummy. In particular, elderly display higher probabilities of transitions into inactivity, but lower probabilities of transitions out of inactivity. Moreover, ther are found to be more persistent in unemployment as compared to the young, who are somewhat more likely to find either salaried and/or self-employment jobs. Household size proves to display two notable effects on labor market transitions. First, we find that the probability of remaining in informal-salaried 
employment increases with the household size, which stems from increased responsibility and financial needs coming with increased household size. Whereas, as household size increases the probability of moving from unemployment to both types of self-employment falls, which may point to the added worker effect.

Sector of economic activity appears to play a fairly significant role in explaining most of the transitions in the labor market. Notably, we find that industrial workers are somewhat more likely to remain as formal-salaried, agricultural workers are less likely to move out of informal selfemployment and construction workers display higher probability of becoming informal-salaried. The results, overall, signify the intrinsic nature of the given sector as an important determinant of the labor market flows.

To conclude, the analysis provides a very comprehensive and detailed diagnosis of the Turkish labor market. The market is observed to display a rather static structure throughout the period we considered. This indicates that a well recognition of underlying dynamics may help policy makers to produce various effective tools for addressing informality. 


\section{REFERENCES}

Aydin, E., M. Hisarciklilar and I. Ilkkaracan (2010), "Formal versus Informal Labor Market Segmentation in Turkey in the Course of Market Liberalization", Topics in Middle Eastern and North African Economies, 12,1-43.

Bernabè, S. (2002), "Informal Employment in Countries in Transition: A Conceptual Framework", LSE Centre for Analysis of Social Exclusion (CASE) Paper No.56, London.

Bernabè, S. and M. Stampini (2009), "Labour Mobility During Transition: Evidence From Georgia", Economics of Transition, 17(2), 377-409.

Bosch, M. and W. Maloney (2005), "Labor Market Dynamics in Developing Countries: Comparative Analysis Using Continuous Time Markov Processes", World Bank Policy Research Working Paper No. 3583.

Bosch, M. and W. Maloney (2007), "Gross Worker Flows in the Presence of Informal Labour Markets. Evidence from Mexico, 1987-2002”, IZA Discussion Paper No. 2864.

Bosch, M. and W. Maloney (2010), "Comparative Analysis of Labor Market Dynamics Using Markov Processes: An Application to Informality”, Labour Economics, 17(4), 621-631.

Bigsten, A., T. Mengistae and A. Shimeles (2007), "Mobility and Earnings in Ethiopia's Urban Labor Markets: 1994-2004", World Bank Policy Research Working Paper No. 4168.

Bukowski, M. and P. Lewandowski (2005), "Transitions From Unemployment in Poland: A Multinomial Logit Analysis", Labor and Demography 0511008, EconWPA.

Bulutay, T. and E. Tasti (2004), "Informal Sector in the Turkish Labour Market", Turkish Economic Association Discussion Paper, No. 2004/22.

Calderon-Madrid, A. (2000), "Job Stability and Labor Mobility in Urban Mexico: A Study Based on Duration Models and Transition Analysis", Inter-American Development Bank Working Paper No. R419.

Canavire-Bacarreza, G. J. and L. F. Soria (2007), "Unemployment Duration and Labor Mobility in Argentina: A Socioeconomic-Based Pre- and Post-Crisis Analysis", CEDLAS Working Papers No. 0054 .

Chen, M. A. (2007), "Rethinking the Informal Economy: Linkages with the Formal Economy and the Formal Regulatory Environment", Dept. of Economic and Social Affairs DESA Working paper No. 46, United Nations.

Cook, S., Q. Deng, M. Wang and N. Yuan (2010), "Towards Gender Equality in China's Economic and Social Transformation: The Rise in Informal Employment and its Impact on Women During China's Economic Transition", Social Protection In Asia Newsletter No. 6.

Duryea, S., G. Marquez, C. Pages and S. Scarpetta (2006), "For Better or For Worse? Job and Earnings Mobility in Nine Middle and Low Income Countries", Brookings Trade Forum, 187203.

Ehrenberg, R. G. and R. S. Smith (1996), Modern Labor Economics: Theory and Public Policy, Reading, MA: Addison-Wesley Longman, Inc.

Fabrizi, E. and C. Mussida (2009), “The Determinants of Labour Market Transitions”, Giornale degli 
Fields, G.S. (1975), "Rural-Urban Migration, Urban Unemployment and Underemployment, and Job Search Activity in LDC's", Journal of Development Economics, 2, 165-187.

Funkhouser, E. (1996), "The Urban Informal Sector in Central America: Household Survey Evidence", World Development, 24(11), 1737-1751.

Funkhouser, E. (1997), "Mobility and Labor Market Segmentation: The Urban Labor Market in El Salvador", Economic Development and Cultural Change, 46(1), 123-153.

Galli, R. and D. Kucera (2004), "Labor Standards and Informal Employment in Latin America", World Development, 32(5), 809-828.

Galli, R. and D. Kucera (2003), "Informal Employment in Latin America: Movements Over Business Cycles and the Effects of Worker Rights", ILO International Institute for Labour Studies Working Paper No. 145/2003.

Gong, X., A. Van Soest and E. Villagomez (2004), "Mobility in the Urban Labor Market: A Panel Data Analysis for Mexico", Economic Development and Cultural Change, 53(1), 1-36.

Gourieroux, C. (1989), Econometrie des Variables Qualitatives, $2^{\text {nd }}$ edition, Paris: Economica. (English version, 2000: Econometrics of Qualitative Dependent Variables, Cambridge Un. Press).

Greene, W.H. (2002), Econometric Analysis, $5^{\text {th }}$ edition, New Jersey: Prentice Hall.

Huitfeldt, H. (1998), "Unemployment and Labour Market Transitions in the Czech Republic: Evidence from Micro-data”, Uppsala University Dept. of Economics Working Paper Series No. 5.

Hussmanns, R. (2005), "Measuring the Informal Economy: From Employment in the Informal Sector to Informal Employment", ILO Policy Integration Department Working Paper No. 53.

ILO (1993), "Resolution Concerning Statistics of Employment in the Informal Sector", Resolution II adopted by the Fifteenth International Conference of Labour Statisticians, Jan. 1993, Geneva.

ILO (2010), Women in Labour Markets: Measuring Progress and Identifying Challenges, International Labor Office, Geneva.

Kan, E. O. (2011), "Essays on Informality in the Turkish Labor Market”, Unpublished PhD Thesis, Middle East Technical University, Ankara.

Kenar, N. (2009), "Informality: Regulations, Institutions and Enforcement", Background paper prepared for the Turkey CEM on Informality.

Krstić, G. and P. Sanfey (2007), "Mobility, Poverty and Well-being Among the Informally Employed in Bosnia and Herzegovina", Economic Systems, 31(3), 311-335.

Lehmann, H. and N. Pignatti (2007), "Informal Employment Relationships and Labor Market Segmentation in Transition Economies: Evidence from Ukraine", IZA Discussion Papers No. 3269.

Maloney, W. (1998), “Are Labor Markets in Developing Countries Dualistic?", The World Bank Policy Research Working Paper Series No. 1941.

Maloney, W. (1999), "Does Informality Imply Segmentation in Urban Labor Markets? Evidence from Sectoral Transitions in Mexico", World Bank Economic Review, 13(3), 275-302. 
Maloney, W. (2004), “Informality Revisited”, World Development, 32(7), 1159-78.

Marcoullier, D., V. Ruiz de Casilla and C. Woodruff (1997), "Formal Measures of the Informal-Sector Wage Gap in Mexico, El Salvador, and Peru", Economic Development and Cultural Change, 45(2), 367-92.

Mazumdar, D. (1976), “The Urban Informal Sector”, World Development, 4(8), 655-679.

Mohan, R. (1986). Work, wages, and welfare in a developing metropolis: consequences of growth in Bogota, Columbia, New York: Oxford University Press.

Pages, C. and M. Stampini (2009), "No Education, No Good Jobs? Evidence on the Relationship Between Education and Labor Market Segmentation", Journal of Comparative Economics, 37(3), 387-401.

Ozdemir, A. M., D. Erel and G. Yücesan-Özdemir (2004), "Rethinking Informal Labour Market in Turkey: A Possible Politics for Unions", South East Europe Review, 7(3), 33-42.

Perry, G., W. Maloney, O. Arias, P. Fajnzylber, A. Mason and J. Saavedra (2007), Informality: Exit and Exclusion, World Bank Latin America and Caribbean Studies, Washington, DC.: The World Bank.

Tansel, A. (1998), "Wage Earners, Self-Employment and Gender in the Informal Sector in Turkey", Background paper prepared for Engendering Development, Washington, DC.: The World Bank.

Tansel, A. (2000) “Formal and Informal Sector Choice of Wage Earners and Their Wages in Turkey', in Bulutay, T. (ed.) Informal Sector I, Ankara: State Institute of Statistics.

Telles, E. (1993), "Urban Labor Market Segmentation and Income in Brazil", Economic Development and Cultural Change, 41(2), 231-249.

TURKSTAT (2011), 2009 Income and Living Conditions Survey, Ankara.

TURKSTAT (2011), 2008 Income and Living Conditions Survey, Ankara.

TURKSTAT (2011), 2006 and 2007 Income and Living Conditions Survey, Ankara.

Woltermann, S. (2002), "Job-Search Methods and Labor Market Transitions in a Segmented Economy: Some Empirical Evidence from Brazil", Ibero-America Institute for Economic Research Discussion Paper No. 88, University of Göttingen.

World Bank (2010), "Turkey Country Economic Memorandum (CEM) on Informality: Causes, Consequences, Policies", Poverty Reduction and Economic Management Unit, Europe and Central Asia Region, Report No. 48523-TR, The World Bank.

Yu, D. (2010), "Defining and Measuring Informal Employment in South Africa: A Review of Recent Approaches", Working Papers 09/2010, Stellenbosch University, Dept. of Economics. 
Table 1a: Turkish Labor Market, distribution of sample labor market states (Age group 15-64 only)

\begin{tabular}{|c|c|c|c|c|c|c|c|c|}
\hline & \multicolumn{2}{|c|}{2006} & \multicolumn{2}{|c|}{2007} & \multicolumn{2}{|c|}{2008} & \multicolumn{2}{|c|}{2009} \\
\hline & $\mathbf{N}$ & $\%$ & $\mathbf{N}$ & $\%$ & $\mathbf{N}$ & $\%$ & $\mathbf{N}$ & $\%$ \\
\hline Formal Salaried (FS) & 4,198 & 15.9 & 4,661 & 17.6 & 5,506 & 20.1 & 5,500 & 19.2 \\
\hline Informal Salaried (IS) & 2,695 & 10.2 & 2,633 & 9.9 & 2,456 & 8.9 & 2,526 & 8.8 \\
\hline Formal Self-Employed (FSE) & 805 & 3.1 & 944 & 3.6 & 1,089 & 3.9 & 981 & 3.4 \\
\hline Informal Self-Employed (ISE) & 4,651 & 17.6 & 4,627 & 17.5 & 4,320 & 15.8 & 4,769 & 16.7 \\
\hline Unemployed (U) & 1,433 & 5.4 & 1,268 & 4.8 & 1,477 & 5.4 & 1,917 & 6.8 \\
\hline Inactive (N) & 12,567 & 47.7 & 12,342 & 46.6 & 12,533 & 45.8 & 12,886 & 45.1 \\
\hline Total & 26,349 & 100 & 26,475 & 100 & 27,381 & 100 & 28,579 & 100 \\
\hline
\end{tabular}

Source: Authors' own calculations based on SILC 2006-2009.

Note: See Appendix Table A1 for category definitions.

Table 1b: Turkish Labor Market, distribution of sample labor market states (Age group 15-64 and Men)

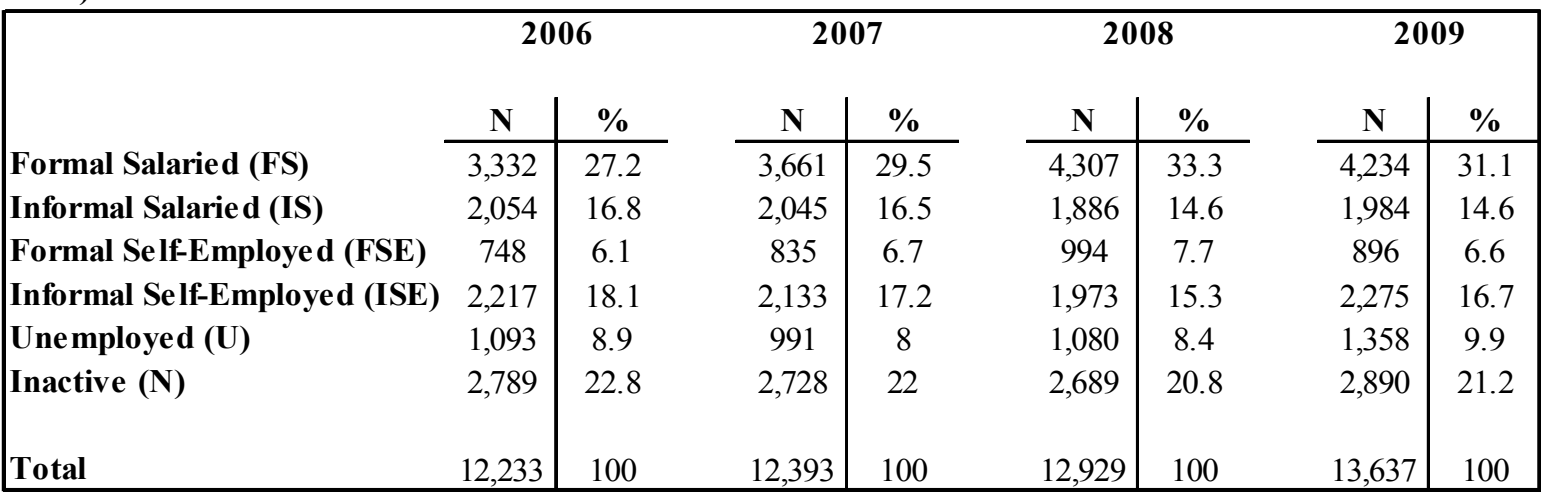

Source: Authors' own calculations based on SILC 2006-2009

Note: See Appendix Table A1 for category definitions.

Table 1c: Turkish Labor Market, distribution of sample labor market state (Age group 15-64 and Women)

\begin{tabular}{|c|c|c|c|c|c|c|c|c|}
\hline & \multicolumn{2}{|c|}{2006} & \multicolumn{2}{|c|}{2007} & \multicolumn{2}{|c|}{2008} & \multicolumn{2}{|c|}{2009} \\
\hline & $\mathbf{N}$ & $\%$ & $\mathbf{N}$ & $\%$ & $\mathbf{N}$ & $\%$ & $\mathbf{N}$ & $\%$ \\
\hline Formal Salaried (FS) & 866 & 6.1 & 1,000 & 7.1 & 1,199 & 8.3 & 1,266 & 8.5 \\
\hline Informal Salaried (IS) & 641 & 4.5 & 588 & 4.2 & 570 & 3.9 & 542 & 3.6 \\
\hline Formal Self-Employed (FSE) & 57 & 0.4 & 109 & 0.8 & 95 & 0.7 & 85 & 0.6 \\
\hline Informal Self-Employed (ISE) & 2,434 & 17.2 & 2,494 & 17.7 & 2,347 & 16.2 & 2,494 & 16.7 \\
\hline Unemployed (U) & 340 & 2.4 & 277 & 1.9 & 397 & 2.8 & 559 & 3.7 \\
\hline Inactive $(\mathbf{N})$ & 9,778 & 69.3 & 9,614 & 68.3 & 9,844 & 68.1 & 9,996 & 66.9 \\
\hline Total & 14,116 & 100 & 14,082 & 100 & 14,452 & 100 & 14,942 & 100 \\
\hline
\end{tabular}

Source: Authors' own calculations based on SILC 2006-2009.

Note: See Appendix Table A1 for category definitions. 
Table 2: Composition of Informality in Total Sample and Non-Agricultural Sample (2006 and 2009 only)

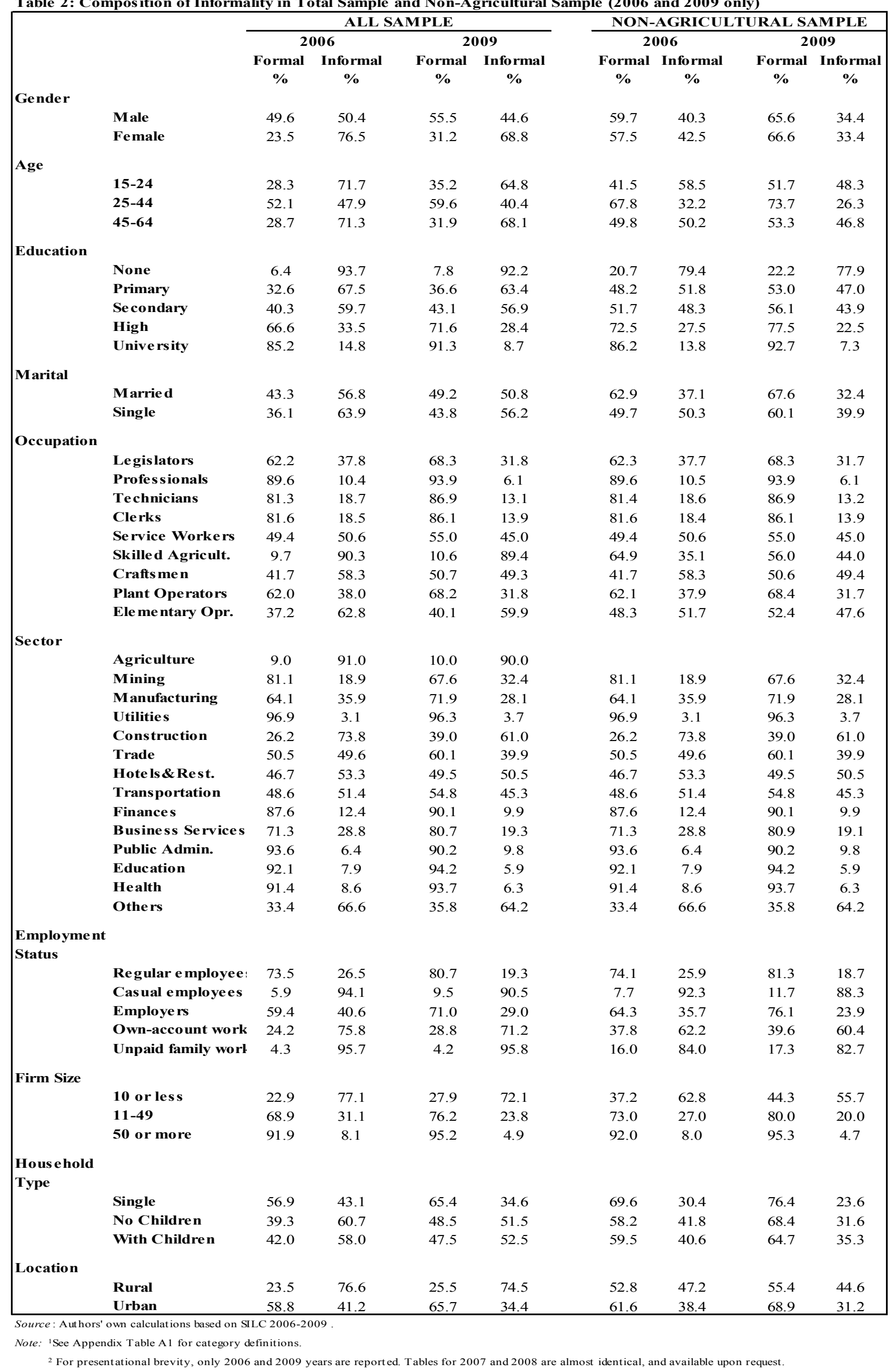




\begin{tabular}{|c|c|c|c|c|c|c|c|c|c|c|c|c|c|c|c|c|c|c|c|c|c|c|c|c|c|}
\hline \multirow{4}{*}{ Gender } & & \multicolumn{6}{|c|}{2006} & \multicolumn{6}{|c|}{2007} & \multicolumn{6}{|c|}{2008} & \multicolumn{6}{|c|}{2009} \\
\hline & & FS & IS & FSE & ISE & $\mathbf{U}$ & $\mathbf{N}$ & FS & IS & FSE & ISE & $\mathbf{U}$ & $\mathbf{N}$ & FS & IS & FSE & ISE & $\mathbf{U}$ & $\mathbf{N}$ & FS & IS & FSE & ISE & $\mathbf{U}$ & $\mathbf{N}$ \\
\hline & & & & & & & & & & & & & & & & & & & & & & & & & \\
\hline & Male & 27.2 & 16.8 & 6.1 & 18.1 & 8.9 & 22.8 & 29.5 & 16.5 & 6.7 & 17.2 & 8 & 22 & 33.3 & 14.6 & 7.7 & 15.3 & 8.4 & 20.8 & 31.1 & 14.6 & 6.6 & 16.7 & 10 & 21.2 \\
\hline & Fe male & 6.1 & 4.5 & 0.4 & 17.2 & 2.4 & 69.3 & 7.1 & 4.2 & 0.8 & 17.7 & 2 & 68.3 & 8.3 & 3.9 & 0.7 & 16.2 & 2.8 & 68.1 & 8.5 & 3.6 & 0.6 & 16.7 & 3.7 & 66.9 \\
\hline \multicolumn{26}{|l|}{ Age } \\
\hline & $15-24$ & 9.0 & 12 & 0.6 & 12.4 & 9.1 & 56.9 & 11.3 & 11.4 & 1 & 12.0 & 8 & 56.3 & 13.5 & 10.1 & 0.9 & 11.0 & 8.8 & 55.8 & 11.5 & 10.5 & 0.5 & 11.9 & 10.3 & 55.2 \\
\hline & $25-44$ & 25.2 & 11.4 & 4.3 & 17.1 & 5.4 & 36.7 & 27.6 & 10.7 & 4.6 & 17.1 & 4.6 & 35.4 & 30.7 & 9.6 & 5.2 & 14.7 & 5.3 & 34.6 & 30 & 9.3 & 4.8 & 15.2 & 6.8 & 33.9 \\
\hline & $45-64$ & 8.2 & 6.9 & 3.5 & 23.3 & 2.2 & 55.9 & 8.4 & 7.5 & 4.3 & 23 & 2.2 & 54.6 & 9.5 & 7.1 & 4.9 & 21.7 & 2.6 & 54.2 & 9.4 & 6.7 & 3.8 & 23.1 & 3.6 & 53.4 \\
\hline \multicolumn{26}{|l|}{ Marital } \\
\hline & Married & 17.6 & 9.6 & 4.0 & 20.1 & 3.4 & 45.4 & 18.6 & 9.5 & 4.6 & 19.9 & 2.9 & 44.5 & 21.1 & 8.6 & 5.1 & 17.6 & 3.6 & 43.9 & 20.6 & 8.3 & 4.4 & 18.7 & 4.7 & 43.3 \\
\hline & Single & 12.4 & 11.6 & 1.0 & 12.4 & 9.8 & 52.7 & 15.5 & 10.8 & 1.3 & 12.3 & 8.8 & 51.3 & 17.6 & 9.8 & 1.1 & 11.3 & 9.8 & 50.3 & 15.9 & 10.1 & 1.1 & 11.8 & 11.7 & 49.5 \\
\hline \multicolumn{26}{|l|}{ Children } \\
\hline & With & 15.9 & 10.6 & 3.1 & 17 & 5.4 & 48 & 17.1 & 10.4 & 3.5 & 16.9 & 4.8 & 47.3 & 19.4 & 9.5 & 4.1 & 15.4 & 5.4 & 46.3 & 18.6 & 9.3 & 3.6 & 16.3 & 6.6 & 52 \\
\hline & No & 16 & 9 & 3 & 19.7 & 5.6 & 46.8 & 19.1 & 8.6 & 3.7 & 19.2 & 4.8 & 44.6 & 22.3 & 7.5 & 3.7 & 16.9 & 5.4 & 44.2 & 21.1 & 7.5 & 3.0 & 17.7 & 7 & 51 \\
\hline \multicolumn{26}{|c|}{ Education } \\
\hline & None & 1.4 & 7.1 & 0.7 & 25.2 & 3.5 & 62.1 & 1.5 & 6.9 & 1.3 & 25 & 2.9 & 62.4 & 2.0 & 7.7 & 1.2 & 24.0 & 3.2 & 62 & 1.8 & 7.3 & 0.9 & 24.8 & 3.5 & 61.8 \\
\hline & Primary & 11.6 & 12.6 & 4.4 & 22.3 & 4.2 & 44.8 & 12.7 & 12.3 & 5.0 & 22.6 & 3.7 & 43.6 & 14.8 & 11 & 6 & 20.4 & 4.3 & 43.5 & 13.1 & 10.6 & 5.2 & 22.3 & 5.5 & 43.4 \\
\hline & Se condary & 13.4 & 11.7 & 2.6 & 12.9 & 6.4 & 52.9 & 15.6 & 11.7 & 2.8 & 12.9 & 6 & 51.1 & 17.5 & 11 & 2.9 & 11.8 & 7.3 & 49.6 & 15.0 & 11.0 & 2.3 & 12.6 & 8.1 & 51 \\
\hline & High & 28.2 & 8.4 & 3.2 & 7.6 & 8.7 & 43.9 & 30.2 & 8.3 & 3.9 & 7.6 & 7.4 & 42.7 & 32.8 & 6.6 & 4 & 6.9 & 7.8 & 41.9 & 32.4 & 7.4 & 4.0 & 7.5 & 10.0 & 38.8 \\
\hline & University & 60.4 & 6 & 2.6 & 3.6 & 7.9 & 19.5 & 63.1 & 4.5 & 2.4 & 3.6 & 6.4 & 20 & 66.8 & 3 & 2.4 & 2.5 & 6.6 & 18.7 & 64.5 & 2.8 & 2.4 & 3.1 & 9.2 & 18 \\
\hline \multicolumn{26}{|l|}{ Sector } \\
\hline & Agriculture & 0.6 & 8.1 & 8.0 & 83.2 & 0 & 0 & 0.7 & 8.2 & 9.2 & 81.8 & 0 & 0 & 1.7 & 8.5 & 10.4 & 79.5 & 0 & 0 & 1.3 & 8.4 & 8.6 & 81.6 & 0.1 & 0.2 \\
\hline & Industry & 63 & 27.0 & 2.4 & 7.6 & 0 & 0 & 67.8 & 23.1 & 3.3 & 5.8 & 0 & 0 & 71.3 & 19.5 & 3.7 & 5.6 & 0 & 0 & 68.8 & 20.1 & 3.3 & 7.4 & 0.1 & 0.3 \\
\hline & Construction & 23.7 & 68.8 & 1.5 & 6.1 & 0 & 0 & 28.0 & 64.5 & 2 & 5.4 & 0 & 0 & 35.9 & 56 & 2.6 & 5.6 & 0 & 0 & 34.9 & 53 & 2.9 & 7.7 & 1.2 & 0.4 \\
\hline & Services & 53.5 & 25.0 & 7.7 & 13.8 & 0 & 0 & 55.5 & 23.1 & 8.3 & 13.1 & 0 & 0 & 59.3 & 19.3 & 9.2 & 12.3 & 0 & 0 & 58.2 & 20.1 & 7.9 & 13.3 & 0.1 & 0.3 \\
\hline \multicolumn{26}{|l|}{ Location } \\
\hline & Rural & 8.8 & 9.1 & 4.6 & 36.2 & 4.0 & 37.4 & 9.9 & 9.3 & 5.5 & 36.1 & 3.6 & 35.6 & 11.6 & 8.8 & 6.2 & 33.6 & 4.2 & 35.5 & 9.7 & 8.6 & 5.2 & 36.3 & 4.3 & 35.9 \\
\hline & Urban & 20.7 & 11 & 2 & 5.2 & 6.4 & 54.6 & 22.8 & 10.4 & 2.3 & 5 & 5.6 & 54 & 25.5 & 9.1 & 2.6 & 4.6 & 6.1 & 52.2 & 24.7 & 9.0 & 2.4 & 5.5 & 8.1 & 50.3 \\
\hline \multicolumn{26}{|c|}{ Firm Size } \\
\hline & 10 or less & 10.6 & 24.0 & 9.7 & 55.7 & 0 & 0 & 12.4 & 22.3 & 11.1 & 54.3 & 0 & 0 & 15.7 & 20.9 & 12.8 & 50.6 & 0 & 0 & 14.5 & 20.9 & 11 & 53.2 & 0.2 & 0.2 \\
\hline & $11-49$ & 69 & 29.7 & 0.1 & 1.2 & 0 & 0 & 69.7 & 29.4 & 0.2 & 0.8 & 0 & 0 & 76.1 & 23.2 & 0 & 0.7 & 0 & 0 & 75.9 & 22.5 & 0.1 & 1.1 & 0 & 0.5 \\
\hline & 50 or more & 91.9 & 8 & 0 & 0.1 & 0 & 0 & 92.8 & 7.2 & 0 & 0 & 0 & 0 & 94.2 & 5.8 & 0 & 0 & 0 & 0 & 94.8 & 4.8 & 0 & 0 & 0.1 & 0.3 \\
\hline \multicolumn{26}{|c|}{ Occupation } \\
\hline & Legislators & 30.6 & 8.5 & 30 & 30.9 & 0 & 0 & 32.5 & 10.4 & 28.9 & 28.2 & 0 & 0 & 34.6 & 7.9 & 30.8 & 26.8 & 0 & 0 & 35.9 & 6.8 & 29.2 & 28 & 0 & 0.1 \\
\hline & Professionals & 87.8 & 7 & 2.7 & 2.6 & 0 & 0 & 89.4 & 5.8 & 2.5 & 2.3 & 0 & 0 & 92.2 & 3.4 & 2.8 & 1.6 & 0 & 0 & 91.2 & 3.8 & 2.6 & 2.0 & 0 & 0.3 \\
\hline & Technicians & 79.5 & 13.6 & 2.1 & 4.8 & 0 & 0 & 81.6 & 10.6 & 3.2 & 4.7 & 0 & 0 & 82.5 & 9.2 & 3.2 & 5.1 & 0 & 0 & 83.7 & 7.1 & 3.3 & 5.5 & 0.1 & 0.4 \\
\hline & Clerks & 81.4 & 16.2 & 0.2 & 2.2 & 0 & 0 & 83.3 & 13.1 & 1.6 & 2.1 & 0 & 0 & 88.1 & 9.6 & 0.7 & 1.6 & 0 & 0 & 84.7 & 12.3 & 0.9 & 1.6 & 0 & 0.6 \\
\hline & Service Workers & 46.7 & 37.1 & 3.1 & 13.2 & 0 & 0 & 47 & 35.2 & 4.3 & 13.6 & 0 & 0 & 51.9 & 29.6 & 6.3 & 12.2 & 0 & 0 & 49.9 & 34.4 & 4.4 & 10.9 & 0.1 & 0.3 \\
\hline & Skill. Agricultu. & 0.6 & 0.5 & 8.7 & 90.1 & 0 & 0 & 0.5 & 0.9 & 10 & 88.6 & 0 & 0 & 0.5 & 0.4 & 11.4 & 87.6 & 0 & 0 & 0.8 & 1.0 & 9.6 & 88.4 & 0.0 & 0.2 \\
\hline & Craftsmen & 35.3 & 46.9 & 5.2 & 12.7 & 0 & 0 & 40.4 & 43.1 & 6.0 & 10.5 & 0 & 0 & 47.7 & 35.1 & 6.6 & 10.7 & 0 & 0 & 43.3 & 34.8 & 6.3 & 14.8 & 0.5 & 0.3 \\
\hline & Plant Operators & 56 & 27.8 & 6 & 10.2 & 0 & 0 & 61.8 & 22.6 & 6.6 & 9 & 0 & 0 & 63.9 & 19.3 & 8.8 & 8.1 & 0 & 0 & 59.8 & 20.9 & 7.8 & 11.2 & 0.1 & 0.2 \\
\hline & Ele mentary Opr. & 36.4 & 53.4 & 0.7 & 9.5 & 0 & 0 & 40.5 & 51.6 & 0.9 & 7.1 & 0 & 0 & 41.6 & 49.8 & 1.1 & 7.5 & 0 & 0 & 38.9 & 42.6 & 1.0 & 16.5 & 0.6 & 0.4 \\
\hline
\end{tabular}

Notes: 'See Appendix Table $\mathrm{Al}$ for variable definitions. ${ }^{2}$ The numbers are given in percentages. 
Table 4a: Transition Probabilities $\left(\mathrm{P}_{\mathrm{ij}}\right)$ 2006-2007 $(\%)$

\begin{tabular}{|c|c|c|c|c|c|c|c|c|c|c|c|c|c|}
\hline \multicolumn{7}{|c|}{$\begin{array}{c}\text { TOTAL SAMPLE } \\
\text { LMS2007 }\end{array}$} & \multicolumn{7}{|c|}{$\begin{array}{l}\text { NON-AGRICULTURAL SAMPLE } \\
\text { LMS2007 }\end{array}$} \\
\hline LMS 2006 & FS & IS & FSE & ISE & $\mathbf{U}$ & $\mathbf{N}$ & LMS 2006 & FS & IS & FSE & ISE & $\mathbf{U}$ & $\mathbf{N}$ \\
\hline FS & 89.3 & 2.8 & 0.4 & 0.9 & 2.7 & 4.1 & FS & 89.8 & 2.7 & 0.4 & 0.4 & 2.7 & 4.1 \\
\hline IS & 12.9 & 57.7 & 0.8 & 7.0 & 9.4 & 12.2 & IS & 15.0 & 59.7 & 0.9 & 3.9 & 9.4 & 11.2 \\
\hline FSE & 3.3 & 2.6 & 78.8 & 12.0 & 0.9 & 2.4 & FSE & 4.3 & 2.1 & 81.9 & 7.5 & 1.1 & 3.2 \\
\hline ISE & 1.3 & 4.0 & 4.5 & 77.3 & 2.0 & 10.9 & ISE & 2.9 & 8.7 & 9.4 & 62.0 & 5.3 & 11.6 \\
\hline $\mathbf{U}$ & 15.2 & 26.4 & 0.7 & 6.0 & 27.9 & 23.8 & $\mathbf{U}$ & 16.3 & 23.7 & 0.8 & 3.2 & 30.3 & 25.8 \\
\hline OLF & 1.7 & 3.3 & 0.2 & 5.4 & 2.7 & 86.7 & OLF & 1.8 & 2.7 & 0.2 & 1.1 & 2.9 & 91.4 \\
\hline P.j (Total) & 17.5 & 10.0 & 3.5 & 18.2 & 4.6 & 46.3 & P.j (Total) & 21.7 & 10.3 & 2.3 & 4.0 & 5.3 & 56.3 \\
\hline
\end{tabular}

Table 4b: Transition Probabilities $\left(P_{\mathrm{ij}}\right)$ 2006-2008 $(\%)$

\begin{tabular}{|c|c|c|c|c|c|c|c|c|c|c|c|c|c|}
\hline \multirow[b]{3}{*}{ LMS 2006} & \multirow{2}{*}{\multicolumn{6}{|c|}{$\begin{array}{l}\text { TOTAL SAMPLE } \\
\text { LMS2008 }\end{array}$}} & \multirow{2}{*}{\multicolumn{7}{|c|}{$\begin{array}{l}\text { NON-AGRICULTURAL SAMPLE } \\
\text { LMS2008 }\end{array}$}} \\
\hline & & & & & & & & & & & & & \\
\hline & FS & IS & FSE & ISE & $\mathbf{U}$ & $\mathbf{N}$ & LMS 2006 & FS & IS & FSE & ISE & $\mathbf{U}$ & $\mathbf{N}$ \\
\hline FS & 85.0 & 3.7 & 0.8 & 1.3 & 3.8 & 5.4 & FS & 78.7 & 4.5 & 0.7 & 2.6 & 6.5 & 7.1 \\
\hline IS & 24.1 & 41.6 & 1.6 & 7.8 & 9.4 & 15.7 & IS & 20.5 & 38.0 & 1.8 & 12.4 & 11.3 & 15.9 \\
\hline FSE & 8.2 & 1.2 & 73.0 & 12.5 & 0.9 & 4.3 & FSE & 6.4 & 3.2 & 60.5 & 20.4 & 1.9 & 7.6 \\
\hline ISE & 3.0 & 5.7 & 6.9 & 65.9 & 1.8 & 16.8 & ISE & 2.7 & 6.2 & 6.3 & 64.6 & 1.8 & 18.5 \\
\hline $\mathbf{U}$ & 21.4 & 23.0 & 1.9 & 9.2 & 23.3 & 21.2 & $\mathbf{U}$ & 17.3 & 16.5 & 3.5 & 10.0 & 27.3 & 25.4 \\
\hline OLF & 2.8 & 3.8 & 0.3 & 7.0 & 3.0 & 83.1 & OLF & 3.6 & 3.5 & 0.2 & 7.7 & 3.2 & 81.7 \\
\hline P.j (Total) & 19.7 & 8.8 & 3.9 & 16.8 & 4.5 & 46.3 & P.j (Total) & 18.8 & 8.4 & 3.5 & 17.5 & 5.6 & 46.3 \\
\hline
\end{tabular}

Notes: $\mathrm{Y}$.j is the relative size of a state at the end ot a period.

FD.Formal-salarled IS:Intormal-Salaried FSE:Formal Selt-employed ISE: Intormal selt-employed U:Unemployed N:Inactive

Table 4c: Transition Probabilities $\left(P_{\mathrm{ij}}\right)$ 2006-2009 $(\%)$

\begin{tabular}{|c|c|c|c|c|c|c|c|c|c|c|c|c|c|}
\hline \multirow{2}{*}{\multicolumn{7}{|c|}{$\begin{array}{l}\text { TOTAL SAMPLE } \\
\text { LMS2009 }\end{array}$}} & \multirow{2}{*}{\multicolumn{7}{|c|}{$\begin{array}{l}\text { NON-AGRICULTURAL SAMPLE } \\
\text { LMS2009 }\end{array}$}} \\
\hline & & & & & & & & & & & & & \\
\hline LMS 2006 & FS & IS & FSE & ISE & $\mathbf{U}$ & $\mathbf{N}$ & LMS 2006 & FS & IS & FSE & ISE & $\mathbf{U}$ & $\mathbf{N}$ \\
\hline FS & 78.7 & 4.5 & 0.7 & 2.6 & 6.5 & 7.1 & FS & 79.6 & 4.4 & 0.7 & 1.5 & 6.6 & 7.3 \\
\hline IS & 20.5 & 38.0 & 1.8 & 12.4 & 11.3 & 15.9 & IS & 23.9 & 38.8 & 1.1 & 8.3 & 12.9 & 14.9 \\
\hline FSE & 6.4 & 3.2 & 60.5 & 20.4 & 1.9 & 7.6 & FSE & 8.8 & 4.4 & 59.3 & 15.4 & 1.1 & 11.0 \\
\hline ISE & 2.7 & 6.2 & 6.3 & 64.6 & 1.8 & 18.5 & ISE & 5.5 & 9.9 & 12.7 & 45.9 & 5.5 & 20.4 \\
\hline $\mathbf{U}$ & 17.3 & 16.5 & 3.5 & 10.0 & 27.3 & 25.4 & $\mathbf{U}$ & 17.9 & 16.3 & 3.3 & 5.4 & 29.6 & 27.5 \\
\hline OLF & 3.6 & 3.5 & 0.2 & 7.7 & 3.2 & 81.7 & OLF & 3.9 & 3.2 & 0.2 & 2.0 & 3.4 & 87.3 \\
\hline P.j (Total) & 18.8 & 8.4 & 3.5 & 17.5 & 5.6 & 46.3 & P.j (Total) & 22.8 & 8.4 & 2.4 & 5.0 & 6.7 & 54.7 \\
\hline
\end{tabular}

Notes: $\quad$ I.j is the relative size of a state at the end of a period.

FS:Formal-salaried IS:Intormal-Salaried FSE:Formal Selt-employed ISE: Intormal Selt-employed U:Unemployed N:Inactive 
Table 4d: Transition Probabilities $\left(P_{i j}\right)$ 2006-2008 (Men only)

\begin{tabular}{|c|c|c|c|c|c|c|c|c|c|c|c|c|c|}
\hline \multicolumn{7}{|c|}{ TOTAL SAMPLE } & \multicolumn{7}{|c|}{ NON-AGRICULTURAL SAMPLE } \\
\hline \multicolumn{7}{|c|}{ LMS2008 } & \multicolumn{7}{|c|}{ LMS2008 } \\
\hline LMS 2006 & FS & IS & FSE & ISE & $\mathbf{U}$ & U & LMS 2006 & FS & IS & FSE & ISE & $\mathbf{U}$ & \\
\hline FS & 85.5 & 4.3 & 0.9 & 1.3 & 3.9 & 4.1 & FS & 86.0 & 4.1 & 0.9 & 0.9 & 4.0 & 4.2 \\
\hline IS & 26.5 & 44.2 & 2.0 & 8.8 & 10.0 & 8.5 & IS & 28.3 & 44.7 & 1.7 & 5.6 & 10.4 & 9.3 \\
\hline FSE & 8.4 & 1.0 & 74.8 & 11.6 & 1.0 & 3.2 & FSE & 8.9 & 1.2 & 78.0 & 6.6 & 1.2 & 4.2 \\
\hline ISE & 5.9 & 9.2 & 12.5 & 62.4 & 2.7 & 7.2 & ISE & 8.6 & 11.0 & 13.5 & 51.4 & 6.2 & 9.3 \\
\hline $\mathbf{U}$ & 21.3 & 26.4 & 2.5 & 10.3 & 25.7 & 13.8 & $\mathbf{U}$ & 22.6 & 25.6 & 2.5 & 6.5 & 27.9 & 14.9 \\
\hline OLF & 5.7 & 8.3 & 1.2 & 7.4 & 6.9 & 70.6 & OLF & 5.9 & 8.5 & 0.7 & 3.3 & 7.3 & 74.3 \\
\hline P.j (Total) & 34.4 & 14.4 & 8.0 & 16.4 & 7.0 & 19.8 & P.j (Total) & 40.9 & 15.1 & 5.3 & 6.8 & 8.4 & 23.6 \\
\hline
\end{tabular}

Source: Authors' own calculations based on SILC 2006-2008 (P anel observations only).

Notes: $\quad{ }^{1} \mathrm{P} . \mathrm{j}$ is the relative size of a state at the end of a period.

${ }^{2}$ FS:Formal-salaried IS:Informal-Salaried FSE:Formal Self-employed ISE: Informal Self-employed U:Unemployed N:Inactive

Table 4e: Transition Probabilities $\left(P_{i j}\right)$ 2006-2008 (Women only)

\begin{tabular}{|c|c|c|c|c|c|c|c|c|c|c|c|c|c|}
\hline \multicolumn{7}{|c|}{ TOTAL SAMPLE } & \multicolumn{7}{|c|}{ NON-AGRICULTURAL SAMPLE } \\
\hline \multicolumn{7}{|c|}{ LMS2008 } & & \multicolumn{6}{|c|}{ LMS2008 } \\
\hline LMS 2006 & FS & IS & FSE & ISE & $\mathbf{U}$ & & LMS 2006 & FS & IS & FSE & ISE & $\mathbf{U}$ & \\
\hline FS & 83.2 & 1.7 & 0.0 & 1.1 & 3.3 & 10.7 & FS & 84.3 & 1.7 & 0.0 & 0.0 & 3.4 & 10.7 \\
\hline IS & 15.8 & 32.8 & 0.0 & 4.4 & 7.5 & 39.5 & IS & 20.8 & 33.9 & 0.0 & 2.6 & 7.3 & 35.4 \\
\hline FSE & 5.3 & 5.3 & 42.1 & 26.3 & 0.0 & 21.1 & FSE & 10.0 & 0.0 & 60.0 & 0.0 & 0.0 & 30.0 \\
\hline ISE & 0.4 & 2.6 & 2.1 & 68.8 & 1.0 & 25.1 & ISE & 0.0 & 6.9 & 9.7 & 41.7 & 2.8 & 38.9 \\
\hline $\mathbf{U}$ & 21.7 & 12.6 & 0.0 & 5.6 & 16.1 & 44.1 & $\mathbf{U}$ & 23.3 & 7.8 & 0.0 & 2.3 & 17.8 & 48.8 \\
\hline OLF & 2.1 & 2.8 & 0.1 & 6.9 & 2.0 & 86.1 & OLF & 2.2 & 1.9 & 0.1 & 1.3 & 2.2 & 92.3 \\
\hline P.j (Total) & 7.7 & 4.2 & 0.6 & 17.1 & 2.5 & 68.0 & P.j (Total) & 9.7 & 3.4 & 0.4 & 1.9 & 2.9 & 81.7 \\
\hline
\end{tabular}

Source: Authors' own calculations based on SILC 2006-2008 (Panel observations only).

Notes: ${ }^{1} \mathrm{P} . \mathrm{j}$ is the relative size of a state at the end of a period.

${ }^{2}$ FS:Formal-salaried IS:Informal-Salaried FSE:Formal Self-employed ISE: Informal Self-employed U:Unemployed N:Inactive

${ }^{3}$ Fore presentational brevity only the tables for 2006-2008 are reported. Transition matrices for 2006-2007 and 2006-2009 panels are available upon request. 
Table 5a: Multinomial Logit es timation results (2006 to 2007 Transitions)

\begin{tabular}{|c|c|c|c|c|c|c|c|c|c|c|c|}
\hline & \multicolumn{5}{|c|}{ MNL 1: Transitions out of Formal-Salaried } & \multicolumn{6}{|c|}{ MNL 2: Transitions out of Informal-Salaried } \\
\hline & FS to IS & FS to FSE & FS to ISE & FS to $\mathbf{U}$ & FS to OLF & & IS to FS & IS to FSE & IS to ISE & IS to $\mathbf{U}$ & IS to OLF \\
\hline fe male & $-1.662 *$ & $-31.78 * * *$ & -1.290 & -0.152 & $0.703 *$ & female & -0.330 & $-33.18 * * *$ & $-1.696^{*}$ & -0.702 & $1.446^{* * *}$ \\
\hline age 25 to 44 & $-2.501 * * *$ & $-4.169 * *$ & -0.225 & -0.545 & $-1.478 * * *$ & age25to44 & -0.0167 & -0.192 & 0.310 & 0.293 & -0.300 \\
\hline age 45 to64 & $-1.389^{*}$ & -3.013 & 0.437 & 0.601 & $1.415^{*}$ & age45to64 & -0.389 & -2.006 & 0.275 & 0.887 & $1.497 * *$ \\
\hline married & -0.115 & $1.650^{*}$ & -1.292 & -0.686 & $-0.750 *$ & married & 0.0487 & 0.574 & -0.600 & -0.461 & -0.550 \\
\hline child & 0.381 & 0.317 & -0.0506 & 0.0972 & 0.0195 & child & -0.309 & -0.437 & -0.0900 & -0.125 & -0.183 \\
\hline hsize & -0.120 & $-1.393 * *$ & -0.330 & -0.165 & $-0.215^{* *}$ & hsize & -0.0403 & -0.226 & $-0.274 * * *$ & $-0.182 * *$ & $-0.181 * * *$ \\
\hline nosch & 0.567 & $-31.74 * * *$ & 1.372 & -0.747 & -0.591 & nosch & -0.664 & $-33.02 * * *$ & 0.520 & $0.661 * *$ & 0.165 \\
\hline secondaryscl & -0.290 & -0.936 & -0.234 & -0.592 & 0.000163 & secondarys cl & -0.165 & -1.454 & -0.554 & -0.471 & $-0.934 * * *$ \\
\hline highsch & $-1.397 * * *$ & 0.944 & $-1.639 * *$ & $-0.790 * *$ & $-0.695 * *$ & highsch & 0.331 & 0.245 & -0.463 & -0.128 & -0.517 \\
\hline unive rsityup & $-1.872 * * *$ & $-32.21 * * *$ & $-2.210^{*}$ & $-2.081 * * *$ & $-1.130 * * *$ & unive rsityup & $0.717^{*}$ & $-32.78 * * *$ & -0.343 & -0.331 & -0.604 \\
\hline exper & -0.0369 & 0.0937 & -0.110 & -0.0938 & $-0.131 * * *$ & exper & $-0.0967 * *$ & $-0.239 * *$ & $-0.0673 *$ & $-0.121 * * *$ & $-0.143 * * *$ \\
\hline expersq & 0.00193 & -0.00158 & 0.00164 & 0.00115 & $0.00333^{* * *}$ & expersq & 0.00152 & $0.00670^{* *}$ & $0.00174 *$ & $0.00198^{*}$ & $0.00322 * * *$ \\
\hline fe mX25to44 & $3.882 * * *$ & $1.901 *$ & 0.523 & 0.122 & 0.302 & femX25to44 & 0.234 & -0.0992 & 0.00989 & -0.00445 & -0.0899 \\
\hline fe mX45to64 & $3.091 *$ & 1.149 & $-32.97 * * *$ & -0.445 & -1.236 & femX45to64 & -0.201 & 1.912 & 0.595 & -0.585 & $-1.318^{*}$ \\
\hline fe mXmar & $-2.381 * *$ & $-2.463^{*}$ & 0.547 & 0.264 & $1.291 *$ & femXmar & -0.624 & -0.700 & 1.164 & -0.170 & 0.816 \\
\hline agriculture & 0.550 & $-33.35^{* * *}$ & $-34.70^{* * *}$ & $-35.47 * * *$ & $-35.97 * * *$ & agriculture & $-1.705 * * *$ & -1.702 & 0.384 & 0.168 & -0.00923 \\
\hline construction & -0.0677 & $-33.11 * * *$ & -0.143 & 0.215 & -0.830 & construction & $-0.588^{*}$ & $-2.027 * *$ & $-0.642 *$ & 0.0763 & -0.517 \\
\hline services & $-0.612 *$ & 0.0731 & -0.383 & $-0.572 *$ & $-0.497^{*}$ & services & $-0.403 *$ & $-1.258^{* *}$ & -0.339 & -0.225 & $-0.497 * *$ \\
\hline fsize 11 to 49 & $-0.901 * *$ & $-33.41 * * *$ & -0.156 & -0.288 & -0.428 & fsize 11 to 49 & $0.677 * * *$ & -0.599 & $-0.933 * *$ & $0.501 *$ & 0.0600 \\
\hline fsize 50plus & $-1.148^{* * * *}$ & $-3.479 * *$ & $-1.625^{*}$ & $-0.899 * *$ & $-0.601^{*}$ & fsize 50plus & $1.093 * * *$ & -0.377 & -0.325 & 0.507 & 0.380 \\
\hline
\end{tabular}

Source: Authors' own calculations based on SILC 2006-2007

${ }^{2}$ FS:Formal-salaried IS:Informal-Salaried FSE:Formal Self-employed ISE: Informal Self-employed U:Unemployed N:Inactive

${ }^{3}$ The results are the marginal effects for the MNL model

${ }^{4}$ Dependent variable Base categor. MNL 1: Remaining in FS, For MNL 2:Remaining in IS, For MNL 3: Remaining in FSE, For MNL 4:Remaining if IS, MNL 5: Remaining in U, MNL 6: Remaining in N

5 Independent variable Base category: Male, Age 15-24, single, does not have a child, primary school graduate, industry sector, firm size 1-10

Legend: $*$ for $\mathrm{p}<.05, * *$ for $\mathrm{p}<.01$, and $* * *$ for $\mathrm{p}<.001$ 
Table 5a: Multinomial Logit es timation results (2006 to 2007 Transitions) continued

\begin{tabular}{|c|c|c|c|c|c|c|c|c|c|c|c|}
\hline \multicolumn{6}{|c|}{ MNL 3: Transitions out of Formal-Self Employed } & \multicolumn{6}{|c|}{ MNL 4: Transitions out of Informal-Se lf Employed } \\
\hline & FSE to FS & FSE to IS & FSE to ISE & FSE to $\mathrm{U}$ & FSE to OLF & & ISE to FS & ISE to IS & ISE to FSE & ISE to $\mathbf{U}$ & ISE to OLF \\
\hline female & $-41.89 * * *$ & $-42.40 * * *$ & $-21.27 * * *$ & $-36.30 * * *$ & $-38.01 * * *$ & female & $-2.016^{*}$ & $-1.331 * *$ & $-1.123^{*}$ & $-1.255^{*}$ & $0.990 * * *$ \\
\hline age 25 to 44 & -0.0966 & $-1.191^{*}$ & -0.800 & $-3.152 * * *$ & $-21.51 * * *$ & age 25 to 44 & -0.109 & -0.475 & 0.320 & -0.873 & $-1.252 * *$ \\
\hline age 45 to64 & -0.647 & -1.987 & -0.465 & 2.237 & $3.586^{*}$ & age 45 to64 & -0.636 & -0.560 & -0.192 & $-2.760 * *$ & $0.905^{*}$ \\
\hline married & -0.539 & -0.838 & $-1.147^{*}$ & $-1.242 *$ & -1.754 & married & -0.822 & 0.395 & 0.355 & -0.297 & -0.148 \\
\hline child & -0.648 & 0.130 & 0.380 & $2.139^{*}$ & -0.0635 & child & -0.373 & -0.296 & $-0.738 * * *$ & -0.0848 & 0.0295 \\
\hline hs ize & 0.0565 & -0.450 & -0.150 & -0.411 & -0.164 & hsize & -0.104 & 0.111 & 0.0180 & -0.0994 & -0.0393 \\
\hline nosch & $-36.35^{* * *}$ & $-37.21 * * *$ & -1.003 & $2.848 * *$ & -0.459 & nosch & -0.774 & 0.0963 & -0.101 & 0.471 & 0.232 \\
\hline s e condarys cl & 0.380 & 0.990 & 0.201 & $-35.63 * * *$ & 0.120 & secondaryscl & -0.0959 & -0.221 & -0.186 & -0.283 & -0.281 \\
\hline highsch & 0.229 & -0.221 & -0.213 & 1.207 & 0.622 & highsch & 0.399 & -0.402 & 0.233 & -0.395 & 0.0392 \\
\hline universityup & -0.809 & 0.282 & $-39.12 * * *$ & $-38.68 * * *$ & $-38.92 * * *$ & universityup & 0.180 & -1.869 & -0.224 & 0.0551 & 0.258 \\
\hline exper & -0.0900 & -0.0410 & -0.0109 & 0.147 & $-0.268^{*}$ & exper & -0.000698 & 0.000781 & -0.0150 & 0.0759 & $-0.106^{* * *}$ \\
\hline expersq & -0.000305 & 0.000952 & 0.000714 & $-0.00821^{*}$ & $0.00559 *$ & expersq & -0.000936 & -0.00108 & 0.000184 & -0.00171 & $0.00179 * * *$ \\
\hline fe mX25to44 & 21.82 & 23.68 & $22.70 * * *$ & 2.399 & 40.90 & fe mX25to44 & -0.618 & 0.510 & -0.724 & 0.159 & $1.303^{*}$ \\
\hline fe mX45to64 & $-9.548 * * *$ & $-11.47 * * *$ & 23.79 & 1.983 & $20.48 * * *$ & fe mX45to64 & $-30.58 * * *$ & 0.274 & 0.177 & 1.858 & -0.275 \\
\hline femXmar & 18.76 & 20.03 & -0.769 & -1.310 & 20.31 & femXmar & -0.0163 & -0.545 & -0.162 & -1.513 & -0.252 \\
\hline agriculture & -0.710 & 0.292 & 0.0611 & $-3.119 * * *$ & $-2.470 * *$ & agriculture & $-1.767 * * *$ & $-2.231 * * *$ & $-2.177 * * *$ & $-2.243 * * *$ & $-1.623 * * *$ \\
\hline construction & 2.548 & $-37.47 * * *$ & $-36.89 * * *$ & 2.038 & $-36.71 * * *$ & construction & -1.906 & -0.611 & $-2.211 * *$ & -1.510 & -0.807 \\
\hline services & -1.144 & -0.442 & -0.551 & $-4.342 *$ & -0.657 & services & $-1.224^{*}$ & $-1.525 * * *$ & $-1.528 * * *$ & $-1.197 * *$ & $-1.216^{* * *}$ \\
\hline & & & & & & fsize 11 to 49 & $-31.92 * * *$ & $2.114^{*}$ & 1.075 & $-32.33 * * *$ & 0.304 \\
\hline & & & & & & fsize 50plus & 29.22 & $27.14 * * *$ & $-8.462 * * *$ & $-7.615^{* * * *}$ & $-8.843 * * *$ \\
\hline
\end{tabular}

Source: Authors' own calculations based on SILC 2006-2007 (Panel observations only).

Notes: ${ }^{1}$ For variable definitions, see Appendix Table A1

${ }^{2}$ FS:Formal-salaried IS:Informal-Salaried FSE:Formal Self-employed ISE: Informal Self-employed U:Unemployed N:Inactive

${ }^{3}$ The results are the marginal effects for the MNL model

${ }^{4}$ Dependent variable Base categor: MNL 1: Remaining in FS, For MNL 2:Remaining in IS, For MNL 3: Remaining in FSE, For MNL 4:Remaining if IS, MNL 5: Remaining in U, MNL 6: Remaining in N

5 Independent variable Base category: Male, Age 15-24, single, does not have a child, primary school graduate, industry sector, firm size 1-10

Legend: * for $\mathrm{p}<.05, * *$ for $\mathrm{p}<.01$, and $* * *$ for $\mathrm{p}<.001$ 
Table 5a: Multinomial Logit estimation results (2006 to 2007 Transitions) continued

\begin{tabular}{|c|c|c|c|c|c|c|c|c|c|c|c|}
\hline & \multicolumn{5}{|c|}{ MNL 5: Transitions out of Une mployed } & \multicolumn{6}{|c|}{ MNL 6: Transitions out of Inactive } \\
\hline & U to FS & U to IS & U to FSE & U to ISE & $\mathbf{U}$ to OLF & & OLF to FS & OLF to IS & OLF to FSE & OLF to ISE & OLF to U \\
\hline female & -0.04 & -0.04 & $-32.79 * * *$ & $-40.42 * * *$ & $1.436^{* *}$ & female & $-1.442 * *$ & $-1.238 * * *$ & $-43.02 * * *$ & $-1.871 * * *$ & $-1.529 * *$ \\
\hline age 25to44 & $-0.973 *$ & $-1.117 * *$ & 0.57 & -0.24 & $-1.421 * *$ & age 25to44 & $-3.873 * *$ & $-1.662 *$ & $-2.126^{*}$ & $-3.462 * * *$ & -0.63 \\
\hline age45to64 & $-1.631^{*}$ & $-1.902 * *$ & $-32.09 * * *$ & 0.14 & 0.16 & age 45to64 & $-5.175 * * *$ & $-2.499 * * *$ & $-3.254 *$ & $-3.732 * * *$ & $-2.356^{* *}$ \\
\hline married & 0.64 & 0.53 & -0.15 & -0.71 & 0.34 & married & $3.038^{*}$ & 0.06 & $2.929 * *$ & 0.38 & -0.11 \\
\hline child & -0.33 & 0.35 & -0.37 & 0.18 & 0.19 & child & 0.07 & 0.43 & $-1.808^{* *}$ & 0.18 & -0.30 \\
\hline hsize & 0.03 & 0.04 & $-0.940 *$ & $-0.259^{*}$ & -0.04 & hsize & -0.18 & -0.13 & -0.11 & -0.11 & $-0.290^{*}$ \\
\hline nosch & -0.79 & 0.06 & $-32.99 * * *$ & -0.36 & 0.13 & nosch & -1.65 & 0.03 & 0.40 & 0.32 & 0.38 \\
\hline secondaryscl & 0.09 & -0.20 & $-33.83^{* * *}$ & -1.08 & -0.33 & s e condarys cl & -0.87 & $-0.815^{* *}$ & -0.27 & $-0.730^{*}$ & 0.06 \\
\hline highsch & $0.700^{*}$ & -0.19 & 0.29 & -0.07 & 0.50 & highs ch & 0.35 & $-0.789 * *$ & $-32.16 * * *$ & $-0.962 * *$ & -0.11 \\
\hline universityup & $1.409^{* *}$ & -0.81 & 1.08 & -0.03 & 0.28 & universityup & 0.65 & -0.33 & $-32.51 * * *$ & $-2.554^{*}$ & 0.01 \\
\hline exper & 0.05 & 0.05 & -0.04 & 0.02 & $-0.103 *$ & exper & -0.07 & 0.02 & -0.21 & $0.0806^{* *}$ & -0.01 \\
\hline expersq & 0.00 & 0.00 & 0.00 & 0.00 & $0.00269 *$ & expersq & 0.00 & 0.00 & 0.00 & $-0.00122^{*}$ & 0.00 \\
\hline femX25to44 & 0.29 & 0.13 & -0.90 & 19.61 & 0.80 & fe mX25to44 & 2.81 & 1.05 & 22.61 & $2.722 * *$ & 0.78 \\
\hline femX45to64 & $-35.63 * * *$ & 1.17 & $34.07 * * *$ & $-17.13 * * *$ & -0.18 & fe mX45to64 & $3.585^{*}$ & 0.49 & $-7.961 * * *$ & $2.216^{* *}$ & 0.20 \\
\hline femXmar & -0.14 & 0.00 & -0.47 & 21.98 & 0.92 & femXmar & $-3.859 * *$ & $-1.302 *$ & 16.39 & -0.81 & -0.98 \\
\hline
\end{tabular}

(Panel observations only)

Notes: ' 'For variable definitions, see Appendix Table Al

${ }^{2}$ FS:Formal-salaried IS:Informal-Salaried FSE:Formal Self-employed ISE: Informal Self-employed U:Unemployed N:Inactive

${ }^{3}$ The results are the marginal effects for the MNL model

${ }^{4}$ Dependent variable Base categor. MNL 1: Remaining in FS, For MNL 2:Remaining in IS, For MNL 3: Remaining in FSE, For MNL 4:Remaining if IS, MNL 5: Remaining in U, MNL 6: Remaining in N

5 Independent variable Base category: Male, Age 15-24, single, does not have a child, primary school graduate, industry sector, firm size 1-10 Legend: $*$ for $\mathrm{p}<.05, * *$ for $\mathrm{p}<.01$, and $* * *$ for $\mathrm{p}<.001$ 
Table 5b: Multinomial Logit estimation results (2006 to 2008 Transitions)

\begin{tabular}{|c|c|c|c|c|c|c|c|c|c|c|c|}
\hline & \multicolumn{5}{|c|}{ MNL 1: Transitions out of Formal-Salaried } & \multicolumn{6}{|c|}{ MNL 2: Transitions out of Informal-Salaried } \\
\hline & FS to IS & FS to FSE & FS to ISE & FS to $\mathbf{U}$ & FS to OLF & & IS to FS & IS to FSE & IS to ISE & IS to $\mathbf{U}$ & IS to OLF \\
\hline female & -1.264 & $-36.89 * * *$ & $-21.59 * * *$ & -0.0403 & 0.562 & female & -0.633 & $-40.79 * * *$ & $-22.52 * * *$ & -0.380 & $0.969^{*}$ \\
\hline age 25 to 44 & $-1.669 * * *$ & $-1.797 *$ & -0.899 & -0.260 & $-1.518 * * *$ & age 25to44 & 0.0417 & -1.373 & 0.707 & -0.00180 & $-1.260^{*}$ \\
\hline age 45to64 & -0.700 & -0.650 & 1.617 & 1.194 & $1.156^{*}$ & age45to64 & $-1.063^{*}$ & -2.502 & 0.367 & -0.250 & 0.908 \\
\hline married & -0.621 & 0.0845 & -1.078 & -0.676 & -0.341 & married & -0.213 & 0.410 & -0.707 & $-0.969 *$ & -0.875 \\
\hline child & 0.148 & 0.377 & -0.198 & -0.104 & -0.294 & child & -0.112 & -0.210 & 0.0107 & -0.179 & -0.340 \\
\hline hs ize & -0.0486 & $-0.572 *$ & -0.293 & 0.0259 & -0.141 & hsize & 0.0988 & -0.265 & $-0.229 *$ & -0.0778 & -0.0566 \\
\hline nosch & -0.801 & $-35.81 * * *$ & $-37.72 * * *$ & -0.997 & $-38.83 * * *$ & nosch & $-1.232 * *$ & $-41.14 * * *$ & -0.101 & -0.0291 & -0.217 \\
\hline secondarys cl & $-0.726^{*}$ & -1.058 & -0.414 & $-1.175^{* *}$ & -0.485 & secondarys cl & -0.193 & -1.894 & $-0.884 *$ & -0.238 & $-0.756^{*}$ \\
\hline highsch & $-1.187 * *$ & -0.559 & -0.618 & $-0.813^{* *}$ & $-0.972 * * *$ & highs ch & 0.438 & 0.423 & -0.755 & -0.235 & 0.00369 \\
\hline universityup & $-1.834 * * *$ & $-36.99 * * *$ & $-2.363^{*}$ & $-1.516^{* * *}$ & $-0.987 * *$ & universityup & $0.982 *$ & $-40.30 * * *$ & $-41.58 * * *$ & -0.249 & -0.301 \\
\hline exper & -0.0413 & 0.125 & -0.00856 & $-0.113^{*}$ & -0.0665 & exper & -0.0000801 & -0.125 & -0.0271 & -0.0514 & -0.0416 \\
\hline expersq & $0.00248^{*}$ & -0.00725 & -0.00116 & 0.00149 & 0.00202 & expersq & -0.000720 & $0.00473^{*}$ & 0.000863 & 0.00135 & 0.00139 \\
\hline femX25to44 & 1.852 & 0.857 & 22.32 & -0.370 & 0.613 & fe mX25to44 & 0.0332 & 0.812 & $20.39 * * *$ & -0.479 & 0.579 \\
\hline fe mX45to64 & 1.759 & 1.540 & $-15.99 * * *$ & $-36.74 * * *$ & -0.485 & fe mX45to64 & 0.908 & 1.241 & 20.00 & -1.230 & -0.825 \\
\hline fe mXmar & -1.529 & -0.610 & 0.226 & -1.208 & 0.805 & fe mXmar & -0.516 & -0.567 & 1.719 & 0.809 & $1.457^{*}$ \\
\hline agriculture & 0.169 & $-36.63 * * *$ & 1.508 & $-37.50 * * *$ & -0.391 & agriculture & $-0.811^{*}$ & -0.434 & 0.0203 & 0.135 & -0.0101 \\
\hline construction & $1.014 *$ & $-35.99 * * *$ & 0.651 & 0.563 & -0.196 & cons truction & $-0.721 * *$ & -1.546 & $-1.118^{* *}$ & 0.247 & $-0.846 *$ \\
\hline services & -0.403 & -0.277 & -0.783 & $-0.734 * *$ & $-0.555^{*}$ & services & -0.105 & -0.206 & -0.308 & 0.0906 & -0.303 \\
\hline fsize 11 to 49 & $-0.837 * *$ & $-1.407^{*}$ & $-1.341^{*}$ & -0.402 & $-0.588^{*}$ & fs ize 11 to 49 & $0.617 * *$ & -0.473 & -0.212 & -0.135 & 0.0901 \\
\hline fsize 50plus & $-1.280 * * *$ & $-2.588 * * *$ & $-1.129 *$ & $-0.623^{*}$ & $-0.552 *$ & fs ize 50plus & 0.423 & -0.432 & -1.876 & 0.284 & 0.277 \\
\hline
\end{tabular}

Notes: 1 For

${ }^{2}$ FS:Formal-salaried IS:Informal-Salaried FSE:Formal Self-employed ISE: Informal Self-employed U:Unemployed N:Inactive

${ }^{3}$ The results are the marginal effects for the MNL model

${ }^{4}$ Dependent variable Base categor: MNL 1: Remaining in FS, For MNL 2:Remaining in IS, For MNL 3: Remaining in FSE, For MNL 4:Remaining if IS, MNL 5: Remaining in U, MNL 6: Remaining in N

5 Independent variable Base category: Male, Age 15-24, single, does not have a child, primary school graduate, industry sector, firm size 1-10 Legend: $*$ for $\mathrm{p}<.05, * *$ for $\mathrm{p}<.01$, and $* * *$ for $\mathrm{p}<.001$ 
Table 5b: Multinomial Logit es timation results (2006 to 2008 Transitions) continued

\begin{tabular}{|c|c|c|c|c|c|c|c|c|c|c|c|}
\hline \multicolumn{6}{|c|}{ MNL 3: Transitions out of Formal-Se If Employed } & \multicolumn{6}{|c|}{ MNL 4: Transitions out of Informal-Se If Employed } \\
\hline & FSE to FS & FSE to IS & FSE to ISE & FSE to $U$ & FSE to OLF & & ISE to FS & ISE to IS & ISE to FSE & ISE to U & ISE to OLF \\
\hline female & 0.0102 & 27.16 & $3.407 * *$ & $-11.65^{* *}$ & $26.19^{* * *}$ & fe male & -1.461 & -0.784 & -1.014 & 0.241 & $1.516^{* * *}$ \\
\hline age 25 to 44 & -0.685 & $-3.614 * * *$ & -0.497 & $-4.103 * *$ & -0.0297 & age25to44 & 0.0147 & -0.755 & 0.471 & 0.979 & -1.18 \\
\hline age 45to64 & -0.0946 & -2.719 & 0.821 & $-3.170 * *$ & $5.773 *$ & age 45to64 & -0.999 & -0.896 & -0.254 & 0.578 & $1.415^{*}$ \\
\hline married & -0.248 & $-2.097^{*}$ & -0.351 & 0.589 & -0.357 & married & 0.331 & $0.966^{*}$ & 0.192 & -0.543 & -0.66 \\
\hline child & 0.460 & $-1.995^{*}$ & -0.388 & -0.151 & -0.411 & child & -0.477 & -0.391 & $-0.524^{*}$ & 0.131 & 0.128 \\
\hline hsize & -0.235 & $-1.327 * * *$ & -0.0668 & -1.081 & -0.0482 & hsize & -0.0608 & $0.163 * *$ & 0.0965 & -0.074 & 0.0309 \\
\hline nosch & $-35.69 * * *$ & $-34.95 * * *$ & 0.204 & 2.892 & 0.982 & nosch & -0.245 & -0.101 & -0.32 & -0.484 & -0.00912 \\
\hline secondarys cl & 0.0886 & $-36.23 * * *$ & -0.253 & 1.136 & 0.826 & secondarys cl & 0.308 & -0.279 & -0.44 & 0.376 & -0.199 \\
\hline highs ch & 0.0414 & $-38.01 * * *$ & -0.403 & $-34.40 * * *$ & 0.873 & highs ch & $1.086^{* *}$ & $-1.267 * *$ & 0.169 & -1.004 & -0.527 \\
\hline univers ityup & 0.774 & 1.380 & -0.432 & $-33.81 * * *$ & $-38.75 * * *$ & universityup & 0.974 & -0.606 & 0.513 & $-31.93 * * *$ & 0.0243 \\
\hline exper & -0.0569 & $0.758^{* * *}$ & -0.0557 & 0.134 & $-0.441 * *$ & exper & -0.0172 & -0.0215 & 0.013 & $-0.124 *$ & $-0.0718 * *$ \\
\hline expersq & -0.000334 & $-0.0194 * * *$ & 0.000798 & -0.00111 & $0.00785 * *$ & expersq & -0.0000594 & -0.000838 & -0.000484 & 0.00198 & $0.00131^{* *}$ \\
\hline fe mX25to44 & -28.78 & $-30.13^{* * *}$ & -57.14 & $-49.65^{* * *}$ & $-40.39 * * *$ & fe mX25to 44 & 0.179 & 0.295 & -0.515 & -0.771 & 1.209 \\
\hline fe mX45to64 & $-41.54 * * *$ & $-47.79 * * *$ & $-32.69 * * *$ & $-30.42 * * *$ & -17.09 & fe mX45to64 & $-28.74 * * *$ & 0.101 & -0.235 & 0.457 & -0.959 \\
\hline fe mXmar & 28.35 & 10.79 & 54.41 & $30.44 * * *$ & $16.49 * *$ & femXmar & -2.345 & -1.237 & -0.578 & -1.561 & 0.143 \\
\hline agriculture & 0.224 & -1.551 & -0.0644 & -2.481 & $-2.705^{*}$ & agriculture & $-1.850^{* * *}$ & $-1.548^{* * *}$ & $-1.915 * * *$ & $-2.545^{* * *}$ & $-1.863 * * *$ \\
\hline cons truction & 0.903 & $-32.77 * * *$ & $-37.09 * * *$ & $-35.76^{* * *}$ & $-39.14 * * *$ & cons truction & $-33.61 * * *$ & 0.078 & -0.758 & -0.484 & -1.316 \\
\hline services & -0.363 & -0.952 & -0.765 & -0.980 & -1.219 & services & $-1.261^{*}$ & $-0.975^{*}$ & $-1.583 * * *$ & -1.054 & $-1.444 * * *$ \\
\hline & & & & & & fsize 11 to 49 & $-30.98 * * *$ & $2.469 * *$ & $-31.85 * * *$ & $-30.23 * * *$ & 0.369 \\
\hline
\end{tabular}

Source: Authors' own calculations based on SILC 2006-2008 (Panel observations only).

Notes: ${ }^{1}$ For variable definitions, see Appendix Table Al

${ }^{2}$ FS:Formal-salaried IS:In formal-Salaried FSE:Formal Self-employed ISE: Informal Self-employed U:Unemployed N:Inactive

${ }^{3}$ The results are the marginal effects for the MNL model

${ }^{4}$ Dependent variable Base categor? MNL 1: Remaining in FS, For MNL 2:Remaining in IS, For MNL 3: Remaining in FSE, For MNL 4:Remaining if IS, MNL 5: Remaining in U, MNL 6: Remaining in N

5 Independent variable Base category: Male, Age 15-24, single, does not have a child, primary school graduate, industry sector, firm size 1-10

Legend: $*$ for $\mathrm{p}<.05, * *$ for $\mathrm{p}<.01$, and $* * *$ for $\mathrm{p}<.001$ 
Table 5b: Multinomial Logit estimation results (2006 to 2008 Transitions) continued

\begin{tabular}{|c|c|c|c|c|c|c|c|c|c|c|c|}
\hline \multicolumn{6}{|c|}{ MNL 5: Transitions out of Une mployed } & \multicolumn{6}{|c|}{ MNL 6: Transitions out of Inactive } \\
\hline & U to FS & U to IS & U to FSE & U to ISE & $\mathbf{U}$ to $\mathbf{O L F}$ & & OLF to FS & OLF to IS & OLF to FSE & OLF to ISE & OLF to $U$ \\
\hline female & $23.72 * * *$ & $23.03 * * *$ & $-10.57 * * *$ & -15.72 & $25.56^{* * *}$ & fe male & $-1.729 * *$ & $-1.554 * * *$ & $-34.26^{* * *}$ & $-1.808^{* * *}$ & $-1.725^{* *}$ \\
\hline age 25 to 44 & -0.821 & -0.248 & 1.374 & 0.0436 & -0.668 & age 25 to 44 & -1.805 & $-1.997 * *$ & -0.833 & $-4.151 * * *$ & -2.155 \\
\hline age 45 to64 & $-36.75^{* * *}$ & -1.191 & 0.866 & -0.388 & 1.024 & age45to64 & $-4.334 * * *$ & $-2.654 * * *$ & -2.963 & $-4.630^{* * *}$ & $-3.783 * * *$ \\
\hline married & 0.39 & 0.228 & 0.553 & -0.365 & 0.465 & married & 0.29 & 0.819 & $4.095 * *$ & $2.080 *$ & 0.516 \\
\hline child & $-1.017^{*}$ & -0.0756 & -0.8 & -0.0405 & -0.702 & child & 0.125 & $0.614 *$ & -0.86 & 0.255 & 0.369 \\
\hline hs ize & 0.148 & 0.043 & -0.298 & -0.23 & -0.0434 & hsize & 0.0538 & -0.15 & -0.355 & $-0.186^{*}$ & -0.285 \\
\hline nosch & -1.44 & -0.247 & 0.11 & -0.178 & 0.319 & nosch & -0.94 & 0.22 & -0.246 & 0.103 & 0.0362 \\
\hline secondarys cl & 0.272 & -0.353 & 0.168 & -0.702 & -0.174 & s econdarys cl & -0.86 & -0.0283 & 0.525 & -0.0705 & -0.208 \\
\hline highsch & $1.026^{*}$ & -0.0639 & 0.159 & -0.436 & 0.554 & highs ch & 0.516 & $-0.713^{*}$ & $-33.20 * * *$ & $-0.678^{*}$ & -0.11 \\
\hline universityup & $2.171^{* *}$ & 0.061 & 0.409 & 0.656 & 1.284 & universityup & $1.305^{*}$ & -0.0523 & $-33.19 * * *$ & $-1.565^{*}$ & -0.807 \\
\hline exper & 0.0442 & 0.0334 & $-0.326 * *$ & -0.0226 & $-0.144 *$ & exper & -0.0762 & -0.00827 & $-0.353^{*}$ & 0.0546 & 0.117 \\
\hline expersq & -0.00071 & -0.000793 & $0.00684 *$ & 0.00191 & $0.00411^{*}$ & expersq & 0.00146 & 0.000204 & $0.00646^{*}$ & -0.000754 & $-0.00368^{*}$ \\
\hline fe mX25to 44 & -22.91 & $-23.41 * * *$ & $-23.74 * * *$ & $-4.491 * * *$ & $-23.48 * * *$ & fe mX25to 44 & 0.63 & $2.225^{* *}$ & 1.126 & $3.724 * * *$ & 2.332 \\
\hline fe mX45to64 & -1.679 & -0.19 & -2.309 & $-19.19 * * *$ & $-3.386^{*}$ & fe mX45to64 & 1.888 & 1.4 & 2.711 & $3.748 * * *$ & 0.771 \\
\hline femXmar & 0.0646 & 0.993 & 0.596 & $22.03 * * *$ & 0.787 & femXmar & -1.154 & $-2.120 * *$ & $-5.048 * * *$ & $-2.294 *$ & $-2.695^{*}$ \\
\hline
\end{tabular}

Notes: ' 'For varıable detinitions, see Appendix I able AI

is:Formal-salared IS.Intormal-Salaried rSE.Fonal selt-employed ISE: Intormal Selt-employed U:Unemployed N:Inactive

The results are the marginal effects for the MNL model

"Dependent varlable Base categor. MNL 1: Remaining in FS, For MNL 2:Remaining in IS, For MNL 3: Remaining in FSE, For MNL 4:Remaining if IS, MNL 5: Remaining in U, MNL 6: Remaining in N

5 Independent variable Base category: Male, Age 15-24, single, does not have a child, primary school graduate, industry sector, firm size 1-10

Legend: $*$ for $\mathrm{p}<.05, * *$ for $\mathrm{p}<.01$, and $* * *$ for $\mathrm{p}<.001$ 
Table 5c: Multinomial Logit es timation results (2006 to 2009 Transitions)

\begin{tabular}{|c|c|c|c|c|c|c|c|c|c|c|c|}
\hline & \multicolumn{5}{|c|}{ MNL 1: Transitions out of Formal-Salaried } & \multicolumn{6}{|c|}{ MNL 2: Transitions out of Informal-Salarie d } \\
\hline & FS to IS & FS to FSE & FS to ISE & FS to $\mathbf{U}$ & FS to OLF & & IS to FS & IS to FSE & IS to ISE & IS to $\mathbf{U}$ & IS to OLF \\
\hline female & $-38.73 * * *$ & $-38.79 * * *$ & $-23.01 * * *$ & -0.820 & $1.069^{*}$ & female & -0.553 & $-39.59 * * *$ & 0.473 & 0.537 & $2.197 * *$ \\
\hline age 25 to 44 & $-1.825^{* *}$ & $-3.128^{*}$ & -0.948 & -0.665 & $-1.274 *$ & age 25to44 & -0.337 & $-3.254 * * *$ & 0.672 & -0.0472 & -0.705 \\
\hline age 45 to64 & -0.815 & $-36.23 * * *$ & 1.119 & -0.685 & 1.283 & age 45 to64 & -1.577 & $-25.13 * * *$ & -0.112 & 1.083 & 0.0567 \\
\hline married & -0.314 & -1.089 & $-1.363^{*}$ & -0.863 & $-1.596^{* *}$ & married & -0.455 & 1.500 & -0.676 & -0.954 & -0.237 \\
\hline child & 0.954 & 1.112 & 0.649 & -0.383 & -0.162 & child & 0.0926 & $-1.714^{* *}$ & 0.262 & -0.421 & -0.541 \\
\hline hsize & -0.212 & -0.871 & -0.138 & -0.0328 & 0.0226 & hsize & 0.0880 & -0.259 & 0.0291 & -0.0990 & -0.0355 \\
\hline nosch & $-42.23^{* * *}$ & $-36.59^{* * *}$ & -0.691 & $-41.21 * * *$ & -1.654 & nosch & $-2.925^{* *}$ & $-42.81 * * *$ & -0.537 & $-1.364 *$ & -0.201 \\
\hline secondarys cl & $-0.981 *$ & -1.355 & $-1.655^{*}$ & -0.00280 & $-1.054 *$ & secondarys cl & -0.0477 & 0.0553 & $-1.535^{* *}$ & -0.802 & -0.832 \\
\hline highsch & $-1.014^{*}$ & -0.773 & -0.987 & -0.609 & $-1.867 * * *$ & highs ch & 0.518 & 0.492 & $-2.648^{*}$ & 0.221 & -0.659 \\
\hline unive rs ityup & $-1.939^{*}$ & $-38.83^{* * *}$ & $-2.711^{*}$ & -0.757 & $-1.169 *$ & universityup & 1.013 & $-40.81 * * *$ & -1.108 & -1.871 & -0.401 \\
\hline exper & -0.0472 & 0.517 & -0.0299 & -0.0210 & 0.0382 & exper & -0.0148 & 0.135 & -0.0928 & 0.0664 & -0.0532 \\
\hline expersq & 0.00249 & -0.0222 & -0.000821 & 0.00114 & -0.000168 & expersq & -0.000747 & -0.00298 & $0.00294 *$ & -0.00264 & $0.00255^{*}$ \\
\hline fe mX25to44 & 18.92 & 18.97 & 22.50 & -0.662 & -0.973 & fe mX25to 44 & 0.220 & $-19.79 * * *$ & -0.843 & 0.187 & -0.268 \\
\hline fe mX45to64 & $-20.56^{* * *}$ & $14.85^{* * *}$ & $-16.39 * * *$ & $-40.24 * * *$ & $-2.536^{*}$ & fe mX45to64 & 0.321 & 43.81 & -0.784 & -2.117 & -1.080 \\
\hline femXmar & 20.20 & 21.13 & $-37.96^{* * *}$ & 0.922 & $2.424^{*}$ & femXmar & 0.177 & 19.39 & 0.895 & 0.967 & 1.029 \\
\hline agriculture & $-39.99 * * *$ & $-37.77 * * *$ & 1.449 & 1.535 & $-41.43^{* * *}$ & agriculture & $-2.026^{*}$ & -0.180 & -0.350 & $-1.473^{*}$ & -0.385 \\
\hline construction & $1.572 * *$ & $-36.57 * * *$ & 0.640 & 0.388 & 0.790 & construction & 0.0958 & -0.305 & -0.899 & 0.108 & -0.997 \\
\hline services & -0.193 & -0.237 & -0.0721 & -0.535 & $-1.078^{* *}$ & services & 0.173 & -0.339 & -0.132 & -0.439 & -0.429 \\
\hline fsize 11 to 49 & -0.718 & -2.153 & -0.0618 & 0.107 & $-0.925^{*}$ & fsize 11 to 49 & $0.791 *$ & -0.993 & -0.616 & 0.123 & -0.626 \\
\hline fsize 50plus & $-1.687 * * *$ & $-39.23^{* * *}$ & $-1.181^{*}$ & -0.431 & -0.173 & fsize 50plus & $1.150^{*}$ & 0.710 & $-43.24 * * *$ & 1.082 & -0.658 \\
\hline
\end{tabular}

Notes: ' $\quad$ ror variable detintions, see Appendix I able AI

FS:Formal-salaried IS:Intormal-Salaried FSE:Formal Selt-employed ISE: Intormal Selt-employed U:Unemployed N:Inactive

The results are the margnal effects for the MNL model

${ }^{4}$ Dependent variable Base categor! MNL 1: Remaining in FS, For MNL 2:Remaining in IS, For MNL 3: Remaining in FSE, For MNL 4:Remaining if IS, MNL 5: Remaining in U, MNL 6: Remaining in N

5 Independent variable Base category: Male, Age 15-24, single, does not have a child, primary school graduate, industry sector, firm size 1-10

Legend: $*$ for $\mathrm{p}<.05, * *$ for $\mathrm{p}<.01$, and $* * *$ for $\mathrm{p}<.001$ 
Table 5c: Multinomial Logit es timation results (2006 to 2009 Transitions) continued

\begin{tabular}{|c|c|c|c|c|c|c|c|c|c|c|c|}
\hline \multicolumn{6}{|c|}{ MNL 3: Transitions out of Formal-Self Employed } & \multicolumn{6}{|c|}{ MNL 4: Transitions out of Informal-Se If Employed } \\
\hline & FSE to FS & FSE to IS & FSE to ISE & FSE to $\mathbf{U}$ & FSE to OLF & & ISE to FS & ISE to IS & ISE to FSE & ISE to $\mathbf{U}$ & ISE to OLF \\
\hline fe male & $-41.66^{* * *}$ & $-38.64 * * *$ & $-20.29 * * *$ & $26.04 *$ & $-3.302 *$ & female & -1.770 & 0.189 & -1.596 & 0.326 & $2.805^{* * *}$ \\
\hline age 25 to 44 & -1.429 & 0.187 & -1.496 & -29.65 & -0.439 & age25to44 & -1.251 & -0.292 & 0.680 & -0.469 & -0.741 \\
\hline age45to64 & -2.276 & 4.180 & -0.373 & $-76.28 * * *$ & 1.571 & age45to64 & $-3.212^{*}$ & -0.0205 & -0.432 & -1.642 & $1.924^{*}$ \\
\hline married & -0.726 & -0.403 & -0.551 & 21.61 & -1.778 & married & 0.254 & $1.885^{* *}$ & 0.595 & 0.252 & -0.0108 \\
\hline child & 0.0562 & -1.317 & 0.483 & 9.919 & -0.426 & child & 0.0424 & -0.757 & -0.361 & -0.333 & 0.134 \\
\hline hsize & -0.493 & 0.222 & -0.136 & $-23.86^{* * *}$ & 0.225 & hsize & -0.136 & $0.206^{*}$ & 0.0404 & -0.191 & 0.000877 \\
\hline nosch & $-37.94 * * *$ & $-34.60 * * *$ & 0.124 & $10.56^{*}$ & 1.145 & nosch & $-34.97 * * *$ & 0.233 & -0.805 & -0.428 & 0.131 \\
\hline se condarys cl & 0.0919 & $2.764 * *$ & 0.517 & $-72.19 * * *$ & 1.097 & se condarys cl & 0.570 & -0.139 & -0.942 & -0.363 & $-1.218^{*}$ \\
\hline highsch & -1.251 & 2.024 & 0.186 & $3.972 *$ & $-39.64 * * *$ & highsch & 0.407 & -0.934 & -0.164 & -1.088 & 0.00641 \\
\hline universityup & 0.989 & $-39.30 * * *$ & 1.003 & $-27.89 * * *$ & 0.115 & universityup & 1.183 & $-36.03 * * *$ & 0.565 & $-35.27 * * *$ & 0.780 \\
\hline exper & 0.00863 & 0.0614 & 0.00195 & -1.697 & -0.00496 & exper & 0.0465 & -0.0920 & -0.0160 & -0.0390 & $-0.0962 * *$ \\
\hline expersq & -0.000980 & -0.00751 & 0.000754 & 0.0479 & 0.000439 & expersq & -0.000431 & 0.0000382 & -0.00000844 & 0.000358 & $0.00168^{*}$ \\
\hline & & & & & & fe mX25to44 & $-32.33 * * *$ & -0.504 & -0.377 & $-35.34 * * *$ & 0.506 \\
\hline fe mX45to64 & $23.21^{* * *}$ & $26.18^{* * *}$ & $22.66^{* * *}$ & $41.41 * * *$ & 22.56 & fe mX45to64 & $-28.90 * * *$ & $-35.71 * * *$ & -0.187 & 1.118 & -1.641 \\
\hline femXmar & 4.520 & -1.629 & 21.65 & -25.25 & 6.494 & femXmar & $-33.24 * * *$ & $-2.081^{*}$ & -0.314 & -1.790 & -0.582 \\
\hline agriculture & 0.760 & -3.545 & -0.266 & 56.43 & $-3.624^{*}$ & agriculture & -1.595 & $-1.765^{* *}$ & $-1.882 * *$ & -1.728 & $-2.529 * * *$ \\
\hline construction & $35.07 * * *$ & $-8.639 * * *$ & $-8.380 * * *$ & $126.0^{* * *}$ & $-8.288^{* * *}$ & construction & $-36.51 * * *$ & 0.840 & -0.232 & 2.043 & $-36.57 * * *$ \\
\hline services & 1.884 & $-3.496^{*}$ & -0.338 & $12.27^{* *}$ & -1.311 & services & -1.051 & $-1.363^{*}$ & $-1.459 *$ & -0.121 & $-1.901 * * *$ \\
\hline & & & & & & fsize 11 to 49 & $-34.80 * * *$ & $2.534 * *$ & $-35.72 * * *$ & $-33.96^{* * *}$ & 0.584 \\
\hline
\end{tabular}

Source: Authors' own calculations based on SILC 2006-2009 (Panel observations only).

Notes: ' For variable definitions, see Appendix Table A1

${ }^{2}$ FS:Formal-salaried IS:Informal-Salaried FSE:Formal Self-employed ISE: Informal Self-employed U:Unemployed N:Inactive

${ }^{3}$ The results are the marginal effects for the MNL model

${ }^{4}$ Dependent variable Base categor: MNL 1: Remaining in FS, For MNL 2:Remaining in IS, For MNL 3: Remaining in FSE, For MNL 4:Remaining if IS, MNL 5: Remaining in U, MNL 6: Remaining in N

5 Independent variable Base category: Male, Age 15-24, single, does not have a child, primary school graduate, industry sector, firm size 1-10

Legend: $*$ for $\mathrm{p}<.05, * *$ for $\mathrm{p}<.01$, and $* * *$ for $\mathrm{p}<.001$ 


\begin{tabular}{|c|c|c|c|c|c|c|c|c|c|c|c|}
\hline & \multicolumn{5}{|c|}{ MNL 5: Transitions out of Une mployed } & \multicolumn{6}{|c|}{ MNL 6: Transitions out of Inactive } \\
\hline & U to FS & U to IS & U to FSE & U to ISE & U to OLF & & OLF to FS & OLF to IS & OLF to FSE & OLF to ISE & OLF to U \\
\hline female & -1.961 & $-38.26^{* * *}$ & $-41.35^{* * *}$ & $-21.45^{* * *}$ & 1.270 & female & $-1.721^{*}$ & $-2.458 *$ & $-40.53 * * *$ & $-2.350 * * *$ & -0.626 \\
\hline age 25 to 44 & -1.472 & 0.0728 & 0.206 & -1.669 & 0.145 & age 25 to 44 & -1.366 & -0.707 & $-58.86^{* * *}$ & $-20.49 * * *$ & $-20.68 * * *$ \\
\hline age 45 to64 & $-39.05^{* * *}$ & 0.268 & $-34.30 * * *$ & -0.877 & 1.399 & age 45 to64 & $-2.209^{*}$ & -1.454 & -20.84 & $-21.85^{* * *}$ & $-21.91 * * *$ \\
\hline married & -0.984 & -0.972 & 1.225 & -0.492 & -1.524 & married & -1.347 & 0.753 & $22.41 * * *$ & $18.89 * * *$ & $21.11 * * *$ \\
\hline child & -0.0446 & 1.122 & 0.143 & 0.655 & -0.0338 & child & 0.773 & $0.848^{*}$ & 0.189 & 0.127 & 0.919 \\
\hline hs ize & 0.0416 & -0.157 & -0.267 & -0.138 & -0.176 & hsize & -0.194 & -0.191 & -0.291 & -0.129 & $-1.086^{* *}$ \\
\hline nosch & -0.709 & -0.0446 & $-34.65 * * *$ & -1.364 & 1.370 & nosch & $-39.57 * * *$ & -0.843 & $-37.96^{* * *}$ & 0.276 & -0.810 \\
\hline secondaryscl & 0.774 & 0.388 & -0.121 & 0.244 & -1.005 & secondarys ct & -0.283 & -0.319 & 0.0739 & 0.487 & 0.222 \\
\hline highsch & 1.058 & 0.522 & 1.441 & -0.948 & $1.477^{*}$ & highs ch & 0.765 & 0.247 & $-37.23 * * *$ & -0.522 & 0.916 \\
\hline universityup & $3.904^{*}$ & $-35.27 * * *$ & 3.017 & 0.670 & 1.342 & unive rsityup & 0.781 & -0.639 & $-37.92 * * *$ & -1.842 & -0.114 \\
\hline exper & 0.186 & 0.0473 & -0.346 & 0.154 & -0.138 & exper & 0.0314 & $-0.122 *$ & -0.329 & 0.0765 & 0.0439 \\
\hline expersq & -0.00497 & -0.00309 & 0.00633 & -0.00469 & $0.00491 *$ & expersq & -0.00275 & $0.00261^{*}$ & 0.00486 & -0.00108 & -0.00310 \\
\hline fe $m X 25$ to 44 & -0.447 & -0.582 & 19.39 & 0.128 & -1.206 & fe mX25to44 & 0.0703 & 0.799 & $59.13 * * *$ & 20.33 & $20.69 * * *$ \\
\hline femX45to64 & 34.96 & 36.16 & $53.35^{* *}$ & -0.356 & 34.19 & fe mX45to64 & 0.294 & 0.152 & $21.89 * * *$ & $21.18 * * *$ & 21.16 \\
\hline fe mXmar & $3.357 *$ & $2.525^{*}$ & 21.97 & 23.28 & $3.762 *$ & femXmar & 0.938 & -0.989 & $-23.02 * * *$ & $-19.08 * * *$ & $-22.94 * * *$ \\
\hline
\end{tabular}

Source: Authors' own calculations based on SILC 2006-2009 (Panel observations only).

Notes: ${ }^{1}$ For variable definitions, see Appendix Table A1

${ }^{2}$ FS:Formal-salaried IS:Informal-Salaried FSE:Formal Self-employed ISE: Informal Self-employed U:Unemployed N:Inactive

${ }^{3}$ The results are the marginal effects for the MNL model

${ }^{4}$ Dependent variable Base categor. MNL 1: Remaining in FS, For MNL 2:Remaining in IS, For MNL 3: Remaining in FSE, For MNL 4:Remaining if IS, MNL 5: Remaining in U, MNL 6: Remaining in N

5 Independent variable Base category: Male, Age 15-24, single, does not have a child, primary school graduate, industry sector, firm size 1-10

Legend: $*$ for $\mathrm{p}<.05, * *$ for $\mathrm{p}<.01$, and $* * *$ for $\mathrm{p}<.001$ 


\section{APPENDIX}

Table A1: List of Definitions

\begin{tabular}{|c|c|c|}
\hline \multicolumn{3}{|l|}{ i. Definition of Labor Market States } \\
\hline Formal Salaried (FS) & \multicolumn{2}{|c|}{ Regular or casual employee who are wage employed AND registered to the Social Security Institution } \\
\hline Informal Salaried (IS) & \multicolumn{2}{|c|}{ Regular or casual employee who are wage employed AND not registered to the Social Security Institution } \\
\hline Formal Self-employed (FSE) & \multicolumn{2}{|c|}{ Self-employed or unpaid family worker AND registered to the Social Security Institution } \\
\hline Informal Self-employed (ISE) & \multicolumn{2}{|c|}{ Self-employed or unpaid family worker AND not registered to the Social Security Institution } \\
\hline Unemployed (U) & \multicolumn{2}{|c|}{ Those who do not work in the reference week BUT available for work AND actively searching } \\
\hline Inactive $(\mathrm{N})$ & \multicolumn{2}{|c|}{ Those who do not work in the reference week, not available for work AND not actively searching } \\
\hline \multicolumn{3}{|c|}{ ii. Definition of Multinomial Logit Model Explanatory Variables } \\
\hline \multicolumn{3}{|l|}{ Gender } \\
\hline & "male" & (Base category) \\
\hline & "female" & Female \\
\hline \multicolumn{3}{|l|}{ Age } \\
\hline & "age 15to24" & (Base category) \\
\hline & "age25to44" & Age $25-44$ \\
\hline & "age45to64" & Age 45-64. \\
\hline \multicolumn{3}{|l|}{ Marital Status } \\
\hline & "single" & not married (Base category) \\
\hline & "married" & married \\
\hline \multicolumn{3}{|l|}{ Education } \\
\hline & "nosch" & Illiterates and individuals who are literate but did not graduate from a school \\
\hline & "primarysch" & Primary school graduate $\quad$ (Base category) \\
\hline & "secondarysch" & Secondary school graduate \\
\hline & "highsch" & High school or vocational school graduate \\
\hline & "universityup" & University or higher graduate \\
\hline \multicolumn{3}{|l|}{ Children } \\
\hline & "nochild" & Does not have children (Base category) \\
\hline & "child" & Has children \\
\hline \multicolumn{3}{|l|}{ Economic Sector } \\
\hline & "agriculture" & Agriculture \\
\hline & "industry" & Mining, manufacturing and utilities (Base category) \\
\hline & "construction" & Construction \\
\hline & "services" & $\begin{array}{l}\text { Trade, hotels and restaurants, transportation, financial intermediation, business services, } \\
\text { public administration, education, health, others. }\end{array}$ \\
\hline \multicolumn{3}{|l|}{ Firm Size } \\
\hline & "fsize 1to10" & Establishments with 1-10 employees (Base category) \\
\hline & "fsize 11 to49" & Establishments with 11-49 employees \\
\hline & "fsize 50plus" & Establishments with50 or more employees \\
\hline \multicolumn{3}{|l|}{ Household Size } \\
\hline & "hsize" & Number of individuals in the household of the survey respondent excluding himself/herself. \\
\hline \multicolumn{3}{|l|}{ Work Experience } \\
\hline & "exper" & Total number of years a survey respondent has worked for. \\
\hline \multicolumn{3}{|l|}{ Female-Age Interaction } \\
\hline & "femX15to24" & Female AND aged 15-24 \\
\hline & "femX25to44" & Female AND aged 25-44 \\
\hline & "femX45to64" & Female AND aged 45-64 \\
\hline \multicolumn{3}{|l|}{ Female-Marital Interaction } \\
\hline & "femXsing" & Female AND single \\
\hline & "femXmar" & Female AND married \\
\hline
\end{tabular}


Table A2-1: Transition Frequencies and Probabilities $\left(P_{\mathrm{ij}}\right)$ 2006-2007

Sector 2007

\begin{tabular}{l|ccccc} 
Sector 2006 & Agriculture & Manufacturing & Construction & Services & Total \\
\hline \multirow{4}{*}{ Agriculture } & & & & & \\
& 2,751 & 24 & 28 & 68 & 2,871 \\
Manufacturing & $\mathbf{9 5 . 8 2}$ & $\mathbf{0 . 8 4}$ & $\mathbf{0 . 9 8}$ & $\mathbf{2 . 3 7}$ & $\mathbf{1 0 0}$ \\
& & & & & \\
& $\mathbf{1 . 9 2}$ & $\mathbf{9 1 . 0 8}$ & $\mathbf{1 . 6 9}$ & $\mathbf{5 . 3 1}$ & $\mathbf{1 0 0}$ \\
Construction & 20 & 15 & 387 & 28 & 450 \\
& $\mathbf{4 . 4 4}$ & $\mathbf{3 . 3 3}$ & $\mathbf{8 6}$ & $\mathbf{6 . 2 2}$ & $\mathbf{1 0 0}$ \\
Services & & & & & \\
& 54 & 68 & 27 & 3,119 & 3,268 \\
Total & $\mathbf{1 . 6 5}$ & $\mathbf{2 . 0 8}$ & $\mathbf{0 . 8 3}$ & $\mathbf{9 5 . 4 4}$ & $\mathbf{1 0 0}$ \\
& 2,850 & 1,291 & 464 & 3,284 & 7,889
\end{tabular}

Table A2-2: Transition Frequencies and Probabilities $\left(P_{i j}\right)$ 2007-2008

Sector 2008

\begin{tabular}{l|ccccc} 
Sector 2007 & Agriculture & Manufacturing Construction & Services & Total \\
\hline \multirow{3}{*}{ Agriculture } & & & & & \\
& 2,643 & 31 & 29 & 65 & 2,768 \\
& $\mathbf{9 5 . 4 8}$ & $\mathbf{1 . 1 2}$ & $\mathbf{1 . 0 5}$ & $\mathbf{2 . 3 5}$ & $\mathbf{1 0 0}$ \\
Manufacturing & & & & & \\
& 31 & 1,187 & 33 & 106 & 1,357 \\
Construction & $\mathbf{2 . 2 8}$ & $\mathbf{8 7 . 4 7}$ & $\mathbf{2 . 4 3}$ & $\mathbf{7 . 8 1}$ & $\mathbf{1 0 0}$ \\
& 16 & & & & \\
& $\mathbf{3 . 1 4}$ & $\mathbf{4 . 7 1}$ & $\mathbf{8 1 . 9 6}$ & $\mathbf{1 0 . 2}$ & $\mathbf{1 0 0}$ \\
Services & & & & & \\
& 49 & 93 & 59 & 3,336 & 3,537 \\
& $\mathbf{1 . 3 9}$ & $\mathbf{2 . 6 3}$ & $\mathbf{1 . 6 7}$ & $\mathbf{9 4 . 3 2}$ & $\mathbf{1 0 0}$ \\
Total & & & & & 8,172 \\
& 2,739 & 1,335 & 539 & 3,559 & $\mathbf{1 0 0}$
\end{tabular}

Table A2-3: Transition Frequencies and Probabilities $\left(P_{\mathrm{ij}}\right)$ 2008-2009

Sector 2009

\begin{tabular}{l|ccccc} 
Sector 2008 & Agriculture & Manufacturing Construction & Services & Total \\
\hline \multirow{4}{*}{ Agriculture } & & & & & \\
& 2,675 & 18 & 20 & 49 & 2,762 \\
Manufacturing & $\mathbf{9 6 . 8 5}$ & $\mathbf{0 . 6 5}$ & $\mathbf{0 . 7 2}$ & $\mathbf{1 . 7 7}$ & $\mathbf{1 0 0}$ \\
& 31 & 1,277 & 19 & 100 & 1,427 \\
& $\mathbf{2 . 1 7}$ & $\mathbf{8 9 . 4 9}$ & $\mathbf{1 . 3 3}$ & $\mathbf{7 . 0 1}$ & $\mathbf{1 0 0}$ \\
Construction & 45 & 13 & 456 & 46 & 560 \\
& $\mathbf{8 . 0 4}$ & $\mathbf{2 . 3 2}$ & $\mathbf{8 1 . 4 3}$ & $\mathbf{8 . 2 1}$ & $\mathbf{1 0 0}$ \\
Services & & & & & \\
& 60 & 58 & 31 & 3,795 & 3,944 \\
Total & $\mathbf{1 . 5 2}$ & $\mathbf{1 . 4 7}$ & $\mathbf{0 . 7 9}$ & $\mathbf{9 6 . 2 2}$ & $\mathbf{1 0 0}$ \\
& & & & & 8,693 \\
& 2,811 & 1,366 & 526 & 3,990 & $\mathbf{1 0 0}$
\end{tabular}

Source: SILC 2006-2007, 2007-2008, 2008-2009 Panel Data

Notes: For each transition 1st row corresponds to the frequency and 2nd row corresponds to probability (\%). 15-64 Age 